\title{
Does Access to Health Care Mitigate Environmental Damages? *
}

\author{
Jamie T. Mullins \\ University of Massachusetts, Amherst \\ Corey White \\ California Polytechnic State University, San Luis Obispo
}

This version: July 16, 2019

\begin{abstract}
Differential access to health care is commonly cited as a source of heterogeneity in environmental health damages, yet little causal evidence exists to support such claims. We address this deficit in two settings by testing whether the negative impacts of ambient temperature exposure on mortality were mitigated by (1) access to primary care through the Community Health Center program, and (2) access to hospital care through the desegregation of Southern hospitals. The results demonstrate that increased access to health care can drive heterogeneity in environmental damages when the mode of care is sufficiently relevant to the damages suffered.
\end{abstract}

JEL: I10, I14, I18, Q50, Q52, Q54, Q58

Keywords: Health Care, Access, Climate, Temperature, Environment

${ }^{*}$ This paper has benefitted from discussions with Alan Barreca, Olivier Deschênes, Teevrat Garg, Andrew Goodman-Bacon, Maya Rossin-Slater, and Heather Royer. The paper has also benefitted from comments and suggestions by seminar participants at the NAREA annual meetings, the University of Oregon, Cal Poly San Luis Obispo, and the University of California, Riverside. 


\section{Introduction}

The scientific understanding of how the environment affects human health has expanded dramatically over the past century, and in recent decades economists have become increasingly involved in this research. One of the most important contributions of economists has been to draw attention to the endogeneity of exposure to environmental insults. This focus has spawned a plethora of studies that employ exogenous variation in exposure to generate causal estimates of marginal damages (see Graff Zivin and Neidell (2013) for a review). At the same time, there has been wide recognition that environmental damages are unevenly distributed across populations (see Banzhaf et al. (2019) for a review). Indeed, many of the studies that provide causal estimates of environmental damages document substantial heterogeneity, often showing that disadvantaged populations suffer the greatest damages. ${ }^{1}$ While such variation in environmental damages has been well documented in a variety of settings, the drivers of this heterogeneity are rarely well understood.

Understanding the sources of heterogeneity in damages is important for determining optimal environmental policy. First, predicting the benefits of a prospective environmental policy requires understanding how the relevant population is likely to be affected. Second, understanding the drivers of heterogeneity can be informative for allocating the marginal dollar. For example, in the context of climate change, it may be more cost effective to invest in adaptation (e.g., investing in health care) rather than mitigation (e.g., investing in low carbon technology).

In a recent review, Hsiang et al. (2019) discuss the importance of precisely identifying the sources of heterogeneity in environmental damages, but also the difficulty in doing so. While causally estimating average marginal damages requires exogenous variation in environmental exposure, causally identifying heterogeneity in marginal damages requires exogenous variation in environmental exposure and in the source of heterogeneity.

There are many potential sources of heterogeneity in environmental health damages, and it has often been posited that differential access to health care is one important driver. We use a causal framework to test this hypothesis in two settings. First, we test whether access to Community Health Centers (hereafter, "CHCs") moderates the relationship between extreme temperatures and general mortality rates in the United States. CHCs increased access to primary care services for low-income individuals in the communities they served. Second, we

\footnotetext{
${ }^{1}$ For example: Chay and Greenstone (2003) and Currie and Walker (2011) each find larger health effects of air pollution among African Americans versus whites. Arceo et al. (2016) find that the effects of carbon monoxide on infant mortality are an order of magnitude larger in Mexico versus the US. Using sub-national data from 41 countries, Carleton et al. (2018) find that the effects of high temperatures on mortality are consistently larger for poorer populations.
} 
test whether the desegregation of hospitals in the Southern US moderates the relationship between extreme temperatures and non-white post-neonatal (ages 1-12 months) mortality rates in the American South. For non-white populations in the South, hospital desegregation dramatically improved access to hospital services.

The direct mortality effects of these two changes in access to health care have been analyzed rigorously in prior studies. Bailey and Goodman-Bacon (2015) study the establishment of CHCs across counties in the period 1965-1974. Bailey and Goodman-Bacon (2015) find that $\mathrm{CHCs}$ reduce mortality rates in the years after initial establishment, that these ameliorative effects grow over time, and that the reductions in general mortality rates are driven primarily by older adults and cardiovascular causes of death. Almond et al. (2006) study the impacts of Southern hospital desegregation on non-white post-neonatal mortality. The authors focus on post-neonatal mortality because of the enormous pre-desegregation race gap in this outcome, and because many potentially fatal conditions for this group could be resolved with hospital-based treatments available at the time. ${ }^{2}$ Almond et al. (2006) find that hospital desegregation led to extremely large decreases in non-white post-neonatal mortality, primarily due to treatable causes such as diarrhea and pneumonia. In two separate analyses, we unite the approaches of Bailey and Goodman-Bacon (2015) and Almond et al. (2006) with the panel-fixed effects methodology that has been widely used to causally identify impacts of temperature on a variety of outcomes including mortality (e.g., Deschênes and Greenstone, 2011; Dell et al., 2014).

We chose these two settings explicitly because they both satisfy a long list of requirements that are necessary for causally identifying the role of access to health care in environmental damages. First, there must exist exogenous variation in both the environmental shock and access to health care. Second, these sources of variation must overlap such that effects of the environmental shock can be estimated before and after the change in access, and for populations that did and did not experience the change. Third, both the environmental shock and the measure of access must plausibly affect the same outcome (e.g., the same causes of death) and the same population (e.g., the same age groups). Fourth, the direct effects of both the environmental shock and the measure of access should exhibit very high statistical power, which is necessary for identifying interaction effects of plausible magnitude.

\footnotetext{
${ }^{2}$ Note that Almond et al. (2006) was accepted for publication at the American Economic Review; ultimately, it was never published for reasons unrelated to the quality of the analysis.
} 
All of these requirements are satisfied in the two settings we analyze. ${ }^{3}$

Our paper is presented in two parts: Part 1 covers our analysis of $\mathrm{CHC}$ access and Part 2 contains our analysis of Southern hospital desegregation. The two parts have parallel structures. In each, we begin with a "replication" model that reproduces findings from prior research on the mortality effects of both the relevant change in health care access and temperature exposures in a single regression. We then construct models to estimate the interaction between access to health care and temperature. Conceptually, our approach in each part is to estimate a difference-in-differences (henceforth, "DiD") model for the effect of changing access to health care on the temperature-mortality relationship. To this end, our models allow for time-invariant differences in the temperature-mortality relationship across treatment groups (analogous to including a treatment group indicator or group fixed effects in a standard DiD), and group-invariant differences in the temperature-mortality relationship over time (analogous to the post-treatment indicator or time fixed effects in a standard DiD). ${ }^{4}$ Together our analyses allow us to consider how two dimensions of improved access to health care (primary care and hospital services) mitigate the relationship between extreme temperatures (both heat and cold) and mortality.

In Part 1 of this paper, our replication model confirms that the improved access to primary care services provided by $\mathrm{CHC}$ reduced the general age-adjusted mortality rate (AMR), ${ }^{5}$ while both cold and hot temperature shocks increase the AMR. Our interaction model indicates that the presence of a $\mathrm{CHC}$ in a county mitigates the relationship between hot temperatures and mortality by approximately $15 \%$. We find no statistically significant evidence that the primary care services provided via CHC access affect the cold-mortality relationship, though the confidence intervals cannot rule out meaningful mitigation effects.

In Part 2, our replication model confirms that desegregation led to large reductions in the non-white post-neonatal mortality rate (PNMR). The same model also shows that while both cold and hot temperature shocks increase the PNMR, the estimated mortality effects

\footnotetext{
${ }^{3}$ We have also considered utilizing other sources of variation in both environmental exposure and access to health care, but found that one or more of these requirements were not satisfied. We considered utilizing the Clean Air Act of 1970, yet much of the variation in air quality occurred at a single point in time; as such, there is a lack of overlap between the variation in air quality and potential changes in access to health care. We also considered the implementation of Medicare, yet Finkelstein and McKnight (2008) find no evidence that Medicare affected mortality, so it is unlikely that it significantly affected temperature-related mortality. Finally, we considered the approach used in Goodman-Bacon (2018b) to identify the effects of Medicaid implementation on non-white child mortality; in this case we collected the necessary data and conducted an analysis, yet we found that the interaction effects were too imprecise to draw any meaningful conclusions. The imprecise interaction effects likely owe to the fact that the direct effects of Medicaid on mortality are underpowered relative to the settings we analyze in this paper.

${ }^{4}$ Analogous controls are used by Hornbeck and Keskin (2014) in the estimation of how aquifer access mitigates the impacts of drought on agricultural yields.

${ }^{5}$ We use "general" to indicate that the AMR represents all deaths (i.e., all ages, causes, races, etc.).
} 
of hot temperatures in this setting are generally small in magnitude and significance. By contrast, the impacts of cold on the PNMR are particularly large in the pre-desegregation period and are driven by pneumonia/influenza and gastroenteritis. These are precisely the same causes of death that Almond et al. (2006) show were prevented by desegregation. Estimates from the interaction model indicate that desegregation dramatically mitigates the relationship between cold and non-white post-neonatal mortality in the South. ${ }^{6}$

Taken together, these results underscore several important points. First, the results from both parts demonstrate that increased access to health care can indeed mitigate environmental health damages. Thus, differential access to care may be one of the drivers behind oft-noted heterogeneity in environmental damages, and particularly differences between rich and poor populations. Second, the results demonstrate that the potential for health care to mitigate environmental damages depends crucially on the specific nature of the health care intervention under consideration and the extent to which the specific intervention is relevant for the same outcomes and populations affected by the environmental insult. Finally, our finding that improved access to primary care services (via CHCs) reduced the negative effects of high temperatures on mortality suggests that increasing access to such preventative health care services may provide an effective means of climate change adaptation.

This paper contributes to an active literature seeking to identify heterogeneity in environmental damages. Several papers set in developing world contexts consider environmental shocks that affect outcomes through changes in income. ${ }^{7}$ Most closely related to our work, however, is a set of papers that explicitly consider heterogeneity in the effects of temperature on mortality: Barreca et al. (2016); Burgess et al. (2017); Banerjee and Maharaj (2018); Cohen and Dechezleprêtre (2018).

Burgess et al. (2017) demonstrate that from 1957-2000, the heat-mortality relationship was much stronger in rural versus urban India. The authors use exogenous variation in bank access to show that a median increase in bank access mitigated the heat-mortality relationship in rural India by approximately $75 \%$. These results imply that bank access was

\footnotetext{
${ }^{6}$ The point estimates suggest mitigation of $100 \%$ of the pre-desegregation white/nonwhite gap in coldrelated mortality, though the confidence intervals imply that mitigation as small as $32 \%$ cannot be ruled out.

${ }^{7}$ Fetzer (2014) demonstrates that access to a workfare program in India (National Rural Employment Guarantee Act - "NREGA") successfully mitigates the relationship between agriculture-affecting rainfall shocks and violence; relaxedly, Sarsons (2015) finds no evidence that dam (i.e., irrigation) access mitigates the rainfall-violence relationship in India. Garg et al. (2018) find that access to NREGA mitigates the relationship between high temperatures and test scores by approximately $38 \%$ in India. Adhvaryu et al. (2018) estimate that a conditional cash transfer program in Mexico (PROGRESA) mitigates the disadvantage caused by early life rainfall shocks by at least $20 \%$. Gunnsteinsson et al. (2018) estimate that Vitamin A supplementation fully mitigates the effect of in-utero exposure to a tornado on infant/childhood growth outcomes in Bangladesh.
} 
able to smooth temperature-induced shocks to agricultural income. Banerjee and Maharaj (2018) is similarly set in India and also focuses on agricultural income as an important mechanism. The authors investigate the relationship between high temperatures and infant mortality in India, and consider two factors that could potentially mitigate the relationship: a workfare program (NREGA) and a health worker program. They find that NREGA has no mitigating impact, whereas 9 months of pre-natal exposure to the health worker program mitigates the relationship between temperature and infant mortality by over $80 \%$. While these estimates are interesting and important, they do not allow for pre-existing differences in the heat-infant-mortality relationship between states that benefitted from the health worker program and those that did not. As such, the estimates may partially reflect such differences. ${ }^{8}$

Cohen and Dechezleprêtre (2018) document the relationship between temperature and mortality in Mexico over the period 1998-2010. The authors find that both cold and hot temperatures are associated with increases in mortality, but the effects of cold (days with mean temperature $<50^{\circ} \mathrm{F}$ ) are much stronger. The authors then test whether enrollment in Mexico's national health insurance program - Seguro Popular - provides protective benefits against temperature-related mortality. This is done by matching enrolled decedents to non-enrolled decedents based on a set of observed characteristics, and then comparing the effects of temperature on mortality for each group. They find that enrollment in Seguro Popular mitigates the mortality effects of a cold day by $35 \%$, and argue that any selection on unobservables likely attenuates this estimate.

In terms of setting, the foundational work of Barreca et al. (2016) is most closely related to ours. The authors demonstrate a "remarkable" decline in the relationship between high temperatures and mortality over the course of the 20th century in the US. This decline was particularly dramatic during a period of rapid expansion in air conditioning technology (henceforth, "AC") after 1960. In Figure 1, we use our own data to show that this decline was remarkable indeed: between 1959 and 1988, the heat-mortality relationship declined by $70 \%$. Interestingly, in the same period the cold-mortality relationship declined by $60 \%$ as well. Barreca et al. (2016) estimate the interaction between temperature and AC penetration, and the results imply that the diffusion of AC technology explains the entire decline in the heatmortality relationship. They also estimate interactions between temperature and the number of doctors per capita and electrification rates, but find no mitigating impacts. However, as the authors note, there does not exist quasi-experimental variation in AC penetration rates or the other potential modifiers. While the interaction estimates undoubtedly represent a

\footnotetext{
${ }^{8}$ This may be a particularly important point given that the roll-out of the health worker program studied by Banerjee and Maharaj (2018) was explicitly non-random, as it was first implemented in Indian states identified as laggards in a variety of public health measures (Rao, 2014).
} 
real and substantial impact of $\mathrm{AC}$ on the heat-mortality relationship, contributions of other simultaneously evolving factors cannot be completely ruled out.

Coinciding with the period of rapid expansion in AC technology was a period of expanding access to health care. The CHC program, Medicare, Medicaid, and Southern hospital desegregation were all implemented beginning in the mid-1960s. Figure 1 shows trends in the US age-adjusted mortality rate ("AMR") and US government spending on health care for our study period, 1959-1988. During this period, government health expenditures as a share of GDP more than tripled, Southern hospitals desegregated, and there was a dramatic $28 \%$ decline in the overall AMR reflecting increased life expectancy and resilience to potential health shocks. In principle, any of the expansions in access to care could have mitigated the health impacts of environmental exposure. In this paper, we focus on the CHC program and hospital desegregation for the practical reasons described above.

While Barreca et al. (2016), Banerjee and Maharaj (2018), and Cohen and Dechezleprêtre (2018) each provide an estimate of how access to health care mitigates the temperaturemortality relationship, to the best of our knowledge our paper is the first to utilize a natural experiment in access to health care to address this question. Our focus on causally identifying whether access to health care mitigates environmental damages is our primary contribution. ${ }^{9}$

The remainder of this paper proceeds as follows: Section 2 provides information on the data sources utilized. Sections 3 and 4 present the background, empirical strategy and results for the analyses of CHCs and hospital desegregation, respectively. Section 5 provides a discussion and concludes.

\section{Data}

This analysis brings together multiple data sources for the period 1959-1988, covering the time period of both CHC establishment and Southern hospital desegregation. ${ }^{10}$ The analysis of CHCs takes place at the county-year-month level, and the analysis of desegregation is at the state-year-month-race level.

Mortality is derived from the National Vital Statistics System mortality files; this is

\footnotetext{
${ }^{9}$ Our paper also contributes to a broader literature in empirical economics aimed at identifying interaction effects by leveraging exogenous variation in multiple treatments. This strategy is particularly prominent in the literature on "dynamic complementarities" in early childhood development (Almond and Mazumder, 2013; Adhvaryu et al., 2018; Johnson and Jackson, 2019; Rossin-Slater and Wüst, 2018). Furthermore, our paper contributes to the rapidly expanding literature on the effects of temperature and climate on health in general. To date, this literature has identified such impacts across a wide variety of outcomes including: mortality (Barreca et al., 2016; Heutel et al., 2017), morbidity (White, 2017; Karlsson and Ziebarth, 2018), mental health (Mullins and White, 2018) and occupational health (Dillender, 2019), and across settings representing over half of the world's population (Carleton et al., 2018).

${ }^{10}$ The sample period matches that used by Bailey and Goodman-Bacon (2015).
} 
individual-level data identifying the county of residence and month of death for each decedent in addition to demographics including age and race, and ICD codes for cause of death. Ageadjusted mortality rates per 100,000 population are calculated using population data from the U.S. Census and National Cancer Institute (SEER Program). Post-neonatal mortality rates per 100,000 births are calculated using birth data from state Vital Statistics Reports and the National Vital Statistics System natality files. ${ }^{11}$ Temperature and precipitation measures are derived from data constructed by the PRISM Climate Group and aggregated by Schlenker and Roberts (2009). Temperature is measured as the mean daily temperature in degrees Fahrenheit (calculated as the mean of the daily minimum and maximum). Data on air conditioning penetration rates are derived from U.S. Census data following Barreca et al. (2016); we construct race-specific AC penetration rates for the desegregation analysis. Additional details on the data are provided in the discussion of the empirical framework for each analysis, but for much greater detail on data sources and construction, see the Data Appendix. Summary statistics for the main mortality outcome, climate variables, and air conditioning are provided in Table 1. Panel A reports summary statistics for all US counties separately for $\mathrm{CHC}$ and non-CHC counties; Panel B reports summary statistics for Southern US states separately for non-whites and whites.

\section{Part 1: Community Health Centers}

\section{$3.1 \quad$ Background}

In our description of CHCs, we provide only the detail necessary for interpretation of our analysis and we refer the reader to Bailey and Goodman-Bacon (2015) for additional detail.

While the CHC program still exists, it has changed in character substantially since its initial implementation (i.e., the period in which our analysis is set). CHCs were clinics or networks of clinics that provided direct and comprehensive primary care services at little or no cost to the patient. These clinics were typically located in neighborhoods with few alternative health care options and served patients who were uninsured, underinsured, or low-income. CHCs often employed multiple clinic locations or mobile units, and over $90 \%$ provided home health care or transportation to appointments (Bailey and Goodman-Bacon, 2015).

The CHC program was initiated in 1965 as part of President Lyndon Johnson's "unconditional war on poverty". It was a grant reward program administered by the Office

\footnotetext{
${ }^{11}$ Post-neonatal mortality is a measure of deaths that occur between 1 month and 1 year of age. This measure is chosen following Almond et al. (2006) as a population for which access to hopsital services is particularly critical.
} 
of Economic Opportunity ("OEO"), which provided direct grants to local organizations for War-on-Poverty programs. Like Bailey and Goodman-Bacon (2015), we rely on the chaotic period known as the "great administrative confusion" at the OEO as a source of quasi-random variation in access to health care. OEO funding decisions during this period (1965-1974) were characterized as "wild", and Bailey and Goodman-Bacon (2015) show little association between the timing of $\mathrm{CHC}$ establishment and pre-treatment county characteristics, mortality rates, changes in mortality rates, funding for other OEO programs, or local expansions in hospital capacity. Following Bailey and Goodman-Bacon (2015), we only utilize variation from the first wave of CHC establishments which took place between 1965 and 1974. The program was fundamentally altered by the 1975 Special Health Revenue Sharing Act which made CHC establishments much less plausibly exogenous and focused them in sparsely-populated rural settings; Bailey and Goodman-Bacon (2015) argue that these later CHCs likely had much smaller impacts on mortality.

CHCs principally provided access to primary and preventative health care, and deaths that could be prevented by such care were heavily concentrated in older adult and elderly populations. Bailey and Goodman-Bacon (2015) note a number of ways in which CHCs may have reduced mortality rates. CHCs may have increased early detection of health conditions, or increased awareness about chronic, yet manageable, conditions like hypertension, which requires continual and long-term medication. Patients would also have been able to get free or reduced-cost pharmaceuticals for the management of such conditions (e.g., beta blockers for hypertension) through CHCs, and the increased continuity of care provided by CHCs likely made it easier for patients to maintain medication regimens. Indirect mechanisms are also plausible: $\mathrm{CHC}$ access may have increased awareness about Medicaid and Medicare, thereby increasing access to treatments for acute conditions. It is also possible that CHCs decreased emergency department usage for non-emergency conditions and thus reduced emergency department crowding; as such, mortality even for non-users of CHCs could have been affected.

Given the dimensions of care provided by CHCs, access might be expected to increase the health stock of served populations. Improvements in the health stock of the population could in turn increase the population's resilience to health shocks, including exposures to extreme temperature. To take a concrete example, suppose that CHCs increased use of antihypertensive medication. Since hypertension is a risk factor for heart attack and stroke, an improvement in hypertension management would have made the population less susceptible to triggers for these events. Indeed, Bailey and Goodman-Bacon (2015) show that CHCs did lead to better hypertension management and that $\mathrm{CHC}$-induced mortality reductions were primarily driven by cardiovascular disease (e.g., heart attack) and cerebrovascular disease (e.g., stroke). If either cold or hot temperatures trigger the events that CHCs prevented, 
then it is at least plausible that increasing $\mathrm{CHC}$ access could reduce temperature-related mortality from such events. The evidence supports this plausibility: for both cold and hot temperatures, we find that cardiovascular and cerebrovascular disease account for $60-70 \%$ of all temperature-related deaths in the pre-CHC period. ${ }^{12}$ We also note that CHCs primarily benefitted the low-income population; to the extent that low-income individuals were also more temperature exposed (e.g., due to lower levels of access to heating and air conditioning), interaction effects are even more plausible. We now turn to testing this hypothesis explicitly.

\subsection{Empirical Strategy}

\subsubsection{Replication Model}

We begin by replicating the effects of both $\mathrm{CHC}$ access on mortality and temperature on mortality in a single econometric model. The model specification follows primarily from Bailey and Goodman-Bacon (2015). Fortunately, the rich set of controls included in Bailey and Goodman-Bacon (2015) are well-suited for identifying ambient temperature effects as well. Our model is distinct from Bailey and Goodman-Bacon (2015) in two ways: (1) our model is estimated at the monthly rather than annual level, and thus some of the fixed effects are adjusted accordingly, and (2) our model includes climatic variables. Equation (1) describes the model.

$$
\begin{aligned}
\mathrm{AMR}_{c y m} & =\gamma \mathrm{CHC}_{c y}^{t \geq 0}+\pi \mathrm{Temp}_{c y m}+\mu \text { LowPrec }_{c y m}+\rho \operatorname{HighPrec}_{c y m} \\
& +\beta \mathrm{X}_{c y}+\delta_{s y}+\delta_{c m}+\delta_{u y}+\delta_{y m}+\varepsilon_{c y m}
\end{aligned}
$$

The outcome of interest is $\mathrm{AMR}_{\text {cym }}$ : the age-adjusted mortality rate in county $c$, year $y$ and month $m .{ }^{13}$ The first coefficient of interest is $\gamma$, where $\mathrm{CHC}_{c y}^{t \geq 0}$ is an indicator equal to one in the years after CHC establishment in a particular county (superscripts indicate years relative to establishment; $t=0$ represents the year in which a $\mathrm{CHC}$ was established). Additional models are presented in which $\mathrm{CHC}_{c y}^{t \geq 0}$ is replaced with a set of binned event-study indicators for periods relative to the year of $\mathrm{CHC}$ establishment: $\mathrm{CHC}_{c y}^{t \leq-2}, \mathrm{CHC}_{c y}^{0 \leq t \leq 4}, \mathrm{CHC}_{c y}^{5 \leq t \leq 9}$, and $\mathrm{CHC}_{c y}^{t \geq 10}(t=-1$ is the reference group). The binned specification follows the main speci-

\footnotetext{
${ }^{12}$ Estimates available upon request.

${ }^{13}$ Age-adjusted mortality rates hold fixed the age distribution of the population of a given county such that changes in the AMR reflect changes in the risk of death rather than changes in the age structure. The AMR for county $c$ at time $t$ is calculated as a weighted average of age-specific mortality rates (ASMR) for county $c$ at time $t$ and 5-year age group $a . A S M R_{c t a}=100,000 \times \frac{D e a t h s_{c t a}}{P_{\text {op }} \text { cta }} ; A M R_{c t}=\sum_{a=1}^{18} s_{c a} \times A S M R_{c t a}$, where $s_{c a}$ is the 1960 share of the population in 5-year age group $a$. Age-adjusting refers to holding the population age share $s_{c a}$ fixed.
} 
fication of Bailey and Goodman-Bacon (2015) and allows for the assessment of differential pre-treatment trends and dynamic treatment effects.

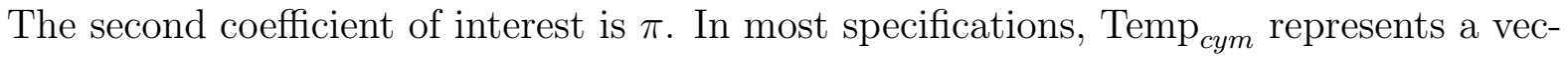
tor of variables measuring the number of days with mean temperatures within the given temperature range in a county-year-month. For example, $\operatorname{Temp}_{c y m}^{<40}$ and Temp $\mathrm{Tym}_{c y m}^{>80}$ represent the number of days below $40^{\circ} \mathrm{F}$ and above $80^{\circ} \mathrm{F}$, respectively. We estimate models that include only two temperature variables (i.e., $\operatorname{Temp}_{\text {cym }}^{<40}$ and Temp $\mathrm{T}_{c y m}^{>80}$ ), and models that include these in addition to intermediate 10-degree bins (i.e., Temp ${ }_{c y m}^{<40}$, Temp ${ }_{c y m}^{40-50}, \operatorname{Temp}_{c y m}^{50-60}$, $\mathrm{Temp}_{\text {cym }}^{70-80}$, and Temp $\mathrm{p}_{\text {cym }}^{>80}$ ). The simpler models are preferred due to the ease of interpretation and the fact that fewer parameters need to be estimated (this is especially important for the interaction models to follow). LowPrec ${ }_{c y m}$ and HighPrec $_{c y m}$ are controls for precipitation. ${ }^{14}$

The remaining controls $\left(\mathrm{X}_{c y}, \delta_{s y}, \delta_{c m}, \delta_{u y}, \delta_{y m}\right)$ are equivalent to the controls used in Bailey and Goodman-Bacon (2015), but adapted to the monthly time scale used here. $\mathrm{X}_{c y}$ is a vector of county-level time-varying covariates. $\delta_{s y}$ are state-by-year fixed effects and $\delta_{u y}$ are urban-group-by-year fixed effects. ${ }^{15} \delta_{c m}$ are county-by-month fixed effects which are used in place of the county fixed effects in Bailey and Goodman-Bacon (2015). In addition to controlling for time-invariant differences across counties, the county-by-month fixed effects control for local-level seasonality. This is potentially important because both temperature and mortality exhibit substantial seasonality, which may differ between regions. $\delta_{y m}$ are year-by-month fixed effects which absorb any nationwide trends or shocks.

Standard errors are two-way clustered at both the county and year-month levels (Cameron et al., 2011). County clustering allows for arbitrary within-county serial correlation and yearmonth clustering allows for arbitrary spatial correlation within a year-month. All regressions are weighted by 1960 county populations.

Identification of $\gamma$ in Equation (1) requires the usual parallel trends assumption for a DiD model: in the absence of treatment, trends in mortality would have been similar between counties in which CHCs were implemented at different dates or not at all. Bailey and Goodman-Bacon (2015) present substantial evidence supporting this identifying assumption, and we refer the inquisitive reader to their work for details. That said, we do present some of this evidence (e.g., pre-treatment effects in the event studies) for comparison with the interaction models that follow.

\footnotetext{
${ }^{14}$ Following Barreca et al. (2016), precipitation controls are indicators for whether total monthly precipitation was below the 25 th percentile or above the 75 th percentile of the county-month distribution.

${ }^{15}$ The time-varying covariates were obtained from Bailey and Goodman-Bacon (2015) and include hospital beds per capita, hospitals per capita, public assistance transfers, and retirement transfers. Also included are linear trends for the following county characteristics measured in 1960: percent with income under $\$ 3,000$, percent non-white, percent rural, percent urban, and number of physicians. The urban-group-by-year fixed effects are year dummies interacted with five categories of a county's 1960 population share in urban areas.
} 
Identification of $\pi$ in Equation (1) requires the assumption that within a given countymonth, year-to-year weather realizations are uncorrelated with other unobserved determinants of mortality. Conditional on county-by-month fixed effects and other controls, yearto-year weather realizations are essentially random and thus this assumption is likely to be satisfied, though we again refer the reader to the work of others for a more detailed discussion (e.g., Deschênes and Greenstone, 2007).

In order to identify the interaction effect between temperatures and CHCs, we require the additional assumption that the two treatments are independent of one-another, conditional on our control regime. Because we are relying on random weather shocks within a countymonth, there is little plausible reason to be concerned that temperature variation is related to the establishment or presence of CHCs. If the treatments are unrelated, as we expect, then the estimated impacts of each treatment should be insensitive to the inclusion of the other treatment in the regression. In our presentation of results, we separately estimate versions of Equation (1) with each treatment in isolation and then including both. We find that the coefficient estimates for both treatments are effectively unchanged across these models. ${ }^{16}$

\subsubsection{Interaction Model}

Summary statistics in Table 1 reveal baseline differences across CHC and non-CHC counties. In particular, $\mathrm{CHC}$ counties had higher average mortality rates in the pre-CHC period (1959-1964) and were slightly warmer on average. These cross-sectional differences across counties in average mortality rates and climate conditions are accounted for through county fixed effects. While these controls are sufficient to separately estimate the effects of either $\mathrm{CHC}$ access or temperature on mortality, causally identifying the interaction requires additional controls. Conceptually, the empirical approach is to estimate a DiD model for the effect of $\mathrm{CHC}$ access on the temperature-mortality relationship. It is likely that there are cross-sectional differences in the temperature-mortality relationship that county fixed-effects would not account for. Our preferred specification for the interaction model explicitly absorbs cross-sectional differences in the temperature-mortality relationship between the CHC and non-CHC counties by allowing temperature effects to differ between these two groups. In this way we ensure our estimates are identified from the change in the temperaturemortality relationship before and after CHC establishment, rather than cross-sectional differences. Practically speaking we are estimating a triple-difference model, described below in Equation (2).

\footnotetext{
${ }^{16}$ Additionally, we test more directly for independence among the two treatments by regressing each treatment on the other and find no significant relationships. Results are presented in Table A1.
} 


$$
\begin{aligned}
\mathrm{AMR}_{c y m} & =\phi\left(\mathrm{CHC}_{c y}^{t \geq 0} \times \operatorname{Temp}_{c y m}\right)+\gamma \mathrm{CHC}_{c y}^{t \geq 0}+\pi \mathrm{Temp}_{c y m} \\
& +\theta\left(\operatorname{Temp}_{c y m} \times \operatorname{Treated}_{c}\right)+\operatorname{Temp}_{c y m} \times \delta_{y}+\kappa\left(\operatorname{Temp}_{c y m} \times \mathrm{AC}_{s y}\right) \\
& +\mu \text { LowPrec }_{c y m}+\rho \operatorname{HighPrec}_{c y m}+\beta \mathrm{X}_{c y}+\delta_{s y}+\delta_{c m}+\delta_{u y}+\delta_{y m}+\varepsilon_{c y m}
\end{aligned}
$$

We allow for fixed differences in the temperature-mortality relationship between $\mathrm{CHC}$ and non-CHC counties through the inclusion of Temp $\mathrm{Temy} \times \operatorname{Treated}_{c}$, where Treated ${ }_{c}$ is an indicator for whether a CHC was ever established in the county over the 1965-1974 period. We also estimate models that control for fixed differences across all counties in the temperature-mortality relationship (directly analogous to county fixed effects in a standard DiD model) by estimating models with county-specific temperature effects: Temp $p_{c y m} \times \delta_{c}$. This requires estimating over 3,000 additional parameters for each temperature variable, and as such we prefer the more parsimonious approach.

Furthermore, just as time fixed effects in a standard $\mathrm{DiD}$ model absorb differences in mortality over time that are common across counties, our interaction model should account for differences in the temperature-mortality relationship over time. To this end, year-specific temperature effects are included: Temp $\mathrm{p}_{\text {cym }} \times \delta_{y}$.

Finally, because the roll-out of CHCs occurred during a period of increasing AC penetration rates, it is potentially important to allow for differential effects of temperature across AC penetration rates. Table 1 shows that $\mathrm{AC}$ penetration rates increased slightly slower in $\mathrm{CHC}$ counties relative to non-CHC counties; as such, failing to control for AC effects would likely bias our estimates toward zero. ${ }^{17}$ Following Barreca et al. (2016), we include the interaction between temperature and the state-year $\mathrm{AC}$ penetration rate: $\mathrm{Temp}_{c y m} \times \mathrm{AC}_{s y}$.

With these controls included, $\phi$ in Equation (2) identifies the change in the temperaturemortality relationship from before to after $\mathrm{CHC}$ establishment, relative to the change in the temperature-mortality relationship in counties where CHCs were established in different years or not at all. The identifying assumption is similar to that of a standard DiD approach: in the absence of treatment, trends in the temperature-mortality relationship would have been similar in counties where CHCs were established in different years. While this assumption is fundamentally un-testable, indirect tests support its plausibility. Most importantly, an event-study version of Equation (2) is estimated to test for differential trends in the temperature-mortality relationship prior to $\mathrm{CHC}$ establishment. We estimate binned event-study versions of Equation (2) as well as a full year-by-year event-study.

\footnotetext{
${ }^{17}$ The likely attenuation bias is under the assumption that access to AC and access to CHCs both affect the temperature-mortality relationship in the same direction.
} 
Further note that the model described in Equation (2) only includes a single variable measuring temperature (for simplicity in exposition). Just as in the replication model, our main specification replaces each instance of Temp cym $_{\text {m }}$ with a vector of two temperature variables $\left(\mathrm{Temp}_{c y m}^{<40}\right.$ and $\left.\mathrm{Temp}_{c y m}^{>80}\right)$. See the appendix for a generalized empirical model that allows for $J$ event-study indicators measuring $\mathrm{CHC}$ access and $G$ temperature bins.

\section{$3.3 \quad$ Results}

\subsubsection{Replication Model}

The results of the replication models are presented in Table 2. The outcome is the ageadjusted mortality rate (AMR) per 100,000 population, and all models include the set of fixed effects and controls described in Equation (1). The models vary in whether and how the effects of each treatment ( $\mathrm{CHCs}$ and temperature) are incorporated. Column 1 starts with a simple model for the effect of $\mathrm{CHC}$ access on mortality with a single indicator for the presence of an established $\mathrm{CHC}$ in a county $\left(\mathrm{CHC}^{t \geq 0}\right)$, excluding all temperature variables. The coefficient estimate indicates that $\mathrm{CHC}$ establishment leads to a significant decrease in the monthly AMR by approximately 1.1. Relative to the pre-CHC mean AMR of 76.5 reported in Table 1, this represents a $1.4 \%$ decrease in the mortality rate.

Column 2 presents estimates from a simple model for the effects of temperature on mortality, excluding any $\mathrm{CHC}$ variables. The coefficient estimates indicate that both cold and hot temperatures lead to increases in mortality. The coefficient on Temp ${ }^{<40}$ implies that one additional day under $40^{\circ} \mathrm{F}$ increases the monthly AMR by 0.11 , relative to a day in the $40-80^{\circ} \mathrm{F}$ range. Temp ${ }^{>80}$ implies one day over $80^{\circ} \mathrm{F}$ increases the monthly AMR by approximately 0.18. Importantly for the estimation of interaction effects that follow, the statistical power is extremely high for all estimates in Columns 1 and 2: the t-statistics for the coefficients on $\mathrm{CHC}^{t \geq 0}$, Temp ${ }^{<40}$, and Temp ${ }^{>80}$ equal 3.6, 7.1 and 9.7, respectively (all are significant at the $0.1 \%$ level) ${ }^{18}$

Columns 1 and 2 demonstrate successful replications of Bailey and Goodman-Bacon (2015) and studies on the effects of temperature on mortality (e.g., Deschênes and Greenstone, 2011; Barreca et al., 2016) using a common econometric framework. Mirroring the results of the replicated studies, our estimates show that CHCs reduce mortality rates and

\footnotetext{
${ }^{18}$ The extreme temperature bins $\left(\mathrm{Temp}_{c y m}^{<40}\right.$ and $\left.\mathrm{Temp}_{c y m}^{>80}\right)$ were chosen primarily to maximize the power of the estimates since high statistical power is necessary to identify interaction effects in the models that follow. While more extreme temperatures such as temperatures $>90^{\circ} \mathrm{F}$ lead to greater damages, these are rare events and the estimates have large standard errors. Furthermore, these events only occur in a select group of counties; for example, of the 114 counties in which CHCs were established in 1965-1974, only 29 counties ever experienced a day with a mean temperature $>90^{\circ} \mathrm{F}$ during the entire 30-year sample period. 107 of these counties experienced $\mathrm{a}>80^{\circ} \mathrm{F}$ day, and 113 experienced $\mathrm{a}<40^{\circ} \mathrm{F}$ day.
} 
extreme temperatures (both hot and cold) increase them. Column 3 includes both treatment variables in a single model. When the $\mathrm{CHC}$ and temperature variables are simultaneously included in the model, the coefficient estimates for each treatment remain virtually unchanged. This reinforces the notion that the variation utilized to identify the effects of these two treatments with respect to mortality are independent and thus identification of interaction effects between the treatments is unlikely to be confounded by some unaddressed interdependence.

The estimates in Columns 4 and 5 use models in which the single CHC indicator is replaced by four indicators for time relative to $\mathrm{CHC}$ establishment (i.e., a binned event-study model) following Bailey and Goodman-Bacon (2015). The coefficient on the pre-treatment $\mathrm{CHC}$ indicator $\left(\mathrm{CHC}^{t \leq-2}\right)$ is not statistically different from zero, indicating no evidence of differential trends in mortality prior to $\mathrm{CHC}$ establishment. The coefficient estimates on the three post-treatment $\mathrm{CHC}$ indicators are all negative, highly significant, and increasing with time relative to $\mathrm{CHC}$ establishment. The results in Column 5 (which includes temperature variables) also closely mirror the results of Bailey and Goodman-Bacon (2015): our coefficient estimates on the $\mathrm{CHC}^{0 \leq t \leq 4}, \mathrm{CHC}^{5 \leq t \leq 9}, \mathrm{CHC}^{t \geq 10}$ bins are -0.82, -1.51, and -1.63, respectively, whereas the coefficient estimates from the equivalent model in Bailey and Goodman-Bacon (2015) are $-0.84,-1.58$, and -1.46 , respectively. ${ }^{19}$ Our estimates for the effects of temperature are not directly comparable to those of Barreca et al. (2016) or similar papers because of differences in outcome measures, sample periods, and model specifications, but the estimates are of qualitatively similar character and magnitude. ${ }^{20}$

Results from an even more flexible replication model are presented in Figure 2. All coefficient estimates in both panels of Figure 2 are from a single regression. The first panel again replicates a result of Bailey and Goodman-Bacon (2015) and reports single-year (as opposed to binned) event study estimates for the effect of CHCs on mortality. These estimates provide more detail on the dynamics of the treatment effects. The estimates again indicate little evidence of differential pre-treatment trends in mortality prior to CHC establishment, and a negative (i.e., ameliorative) treatment effect that emerges post-treatment and grows over time. A similar single-year event-study will be estimated in the next section for the effects of CHCs on the temperature-mortality relationship.

The second panel of Figure 2 reports coefficient estimates for five 10-degree temperature bins $\left(60-70^{\circ} \mathrm{F}\right.$ is excluded), which were included in the model in place of the two extreme

\footnotetext{
${ }^{19}$ Because the Bailey and Goodman-Bacon (2015) model is estimated at the annual level, the coefficients from their paper were divided by 12 to scale the coefficients down to the monthly level.

${ }^{20}$ The differences between our analyses and those of Barreca et al. (2016) inclue the following. Our sample is 1959-1988 while the most-comparable Barreca et al. (2016) sample is $1960-2004$. We use only $<40^{\circ} \mathrm{F}$ and $>80^{\circ} \mathrm{F}$, whereas Barreca et al. (2016) use all 10-degree bins between $<10^{\circ} \mathrm{F}$ and $>90^{\circ} \mathrm{F}$. Finally, our outcome is the age-adjusted mortality rate in levels (at the county level), whereas Barreca et al. (2016) use the $\log$ crude mortality rate (at the state level).
} 
bins only. This yields the familiar U-shaped relationship between temperature and mortality that has been well documented in the prior literature. ${ }^{21}$

\subsubsection{Interaction Model}

Table 3 presents the results of the interaction models. ${ }^{22}$ The columns vary the controls that are included in the model, though all models include the same set of fixed effects and covariates that were included in the replication models. Column 1 is the simplest specification that includes all of the controls necessary for identifying the interaction effect. Specifically, it allows for time-invariant differences in the effects of temperature across $\mathrm{CHC}$ and non-CHC counties (Temp $\times$ Treated) and for location-invariant differences in the effects of temperature over time $\left(\right.$ Temp $\left.\times \delta_{y}\right)$. Column 2 allows for the effects of temperature to vary across AC penetration rates. Finally, Column 3 replaces the Temp $\times$ Treated controls with the more general Temp $\times \delta_{c}$ controls. These county-specific temperature effects represent over 3,000 additional parameters for each temperature variable, absorbing arbitrary fixed differences across all counties in the temperature-mortality relationship. Column 2 is our preferred specification as it includes all necessary controls while not asking as much of the data as the specification in Column 3. All interaction models include the main effects for both temperature and $\mathrm{CHC}$ access, however we present only the coefficients on the interactions for brevity. ${ }^{23}$

We begin with Panel A, which presents estimates using a single post-CHC indicator. The coefficient on $\mathrm{CHC}^{t \geq 0} \times \mathrm{Temp}^{<40}$ interaction represents the change in the effect of cold temperatures on mortality that can be attributed to $\mathrm{CHC}$ access. Across all three specifications, we find no evidence that CHC access has a significant impact on the cold-

\footnotetext{
${ }^{21}$ The estimate for the coefficient on Temp $<40$ in this model with five bins is larger compared to the model with only the extreme bins in Table 2. The larger coefficient estimate in the five-bin model owes to the fact that the omitted group for the model in Table 2 includes all days with mean temperatures in the range of $40-80^{\circ} \mathrm{F}$. Since temperatures in the $40-60^{\circ} \mathrm{F}$ range negatively impact mortality relative to the $60-70^{\circ} \mathrm{F}$ temperature bin, the coefficient estimate for Temp $<40$ is attenuated when these days are included in the reference group. There is little difference in the coefficient estimate for Temp ${ }^{>80}$ between the two models. For the interaction models, these results imply that a model including only the extreme temperature bins may provide conservative estimates for the interaction between CHCs and cold temperatures. While our preferred specification for the interaction model includes only the extreme temperature bins to facilitate interpretability, we also estimate interaction models with all five bins.

${ }^{22}$ Tables A2 and A3 present alternative versions of our main results. Table A2 presents a version that uses all five temperature bins (instead of only the extreme bins), and Table A3 presents models that trim the sample based on the probability (propensity score) of CHC establishment. These results are discussed in the Online Appendix.

${ }^{23}$ Furthermore, while the direct effects for CHC access in the interaction models have a meaningful interpretation, the interpretation of the direct effects for temperature are obscured by the controls that include temperature interactions (e.g., Temp $\times$ Treated and Temp $\times \delta_{y}$ ). In any case, these additional estimates are available upon request.
} 
mortality relationship. We next turn to hot temperatures. The coefficient estimate on $\mathrm{CHC}^{t \geq 0} \times \mathrm{Temp}^{>80}$ in Column 1 yields a negative and statistically significant interaction term. The coefficient estimate changes little when AC effects are included in Column 2. Finally, the magnitude of the estimate is also insensitive to inclusion of county-specific temperature effects in Column 3, though the standard errors increase substantially (nevertheless, the estimate remains significant at the $10 \%$ level).

The coefficient estimate in our preferred specification in Column 2 is -0.052 ; this represents the causal effect of $\mathrm{CHC}$ access on the heat-mortality relationship, and the negative sign indicates that $\mathrm{CHC}$ access mitigates the temperature-mortality relationship. Specifically, the estimate implies that $\mathrm{CHC}$ access mitigates the harmful effect of heat on mortality by $15.3 \%$, measured relative to the heat-mortality relationship in CHC counties in the preCHC period. ${ }^{24}$ It is worth noting that while we find no statistically significant evidence of mitigation for the effects of cold temperatures, our $95 \%$ confidence intervals cannot rule out implied mitigation impacts of up to $10.8 \%$.

In Panel B, we consider models that allow for dynamic treatment effects in a binned event-study framework. In all dynamic specifications, the year prior to CHC establishment $(t=-1)$ is the omitted category and so all dynamic effects are measured relative to that year.

The $\mathrm{CHC}^{t \leq-2} \times \mathrm{Temp}^{<40}$ and $\mathrm{CHC}^{t \leq-2} \times \mathrm{Temp}^{\geq 80}$ interactions measure the "effect" of $\mathrm{CHC}$ access on the cold- and heat-mortality relationships in all periods two years or more before CHC establishment, relative to one year prior. These estimates therefore represent tests for differential trends in the temperature-mortality relationship prior to CHC establishment. If our identification strategy is valid, we expect the estimates of these coefficients to be near zero.

Across all three specifications, the coefficient estimates on both $\mathrm{CHC}^{t \leq-2} \times \mathrm{Temp}^{<40}$ and $\mathrm{CHC}^{t \leq-2} \times \mathrm{Temp}^{\geq 80}$ are small and statistically insignificant, indicating no evidence of differential pre-treatment trends in the temperature-mortality relationship.

The estimates for the post-treatment interactions with cold temperatures again yield no statistically significant evidence of an effect of CHCs on the cold-mortality relationship. The estimates for the post-treatment interactions with high temperatures are all negative (implying mitigation) and tend to increase in magnitude with years since establishment.

The binned approach in Panel B of Table 3 groups together years relative to CHC establishment to maximize the power of the dynamic estimates. As a final way of presenting

\footnotetext{
${ }^{24}$ To calculate the temperature-mortality relationship in CHC counties for the pre-CHC period, we limit the sample to only CHC counties in 1959-1965, and estimate the model presented in Column 2 of Table 2. The coefficient on Temp ${ }^{>80}$ equals 0.339 (s.e. $=0.070$ ), and the coefficient on Temp ${ }^{<40}$ equals 0.241 (s.e. $=0.081$ ).
} 
these results, we estimate a version of Equation (2) as a year-by-year event study (see Equation (5) in the Appendix for a full description of the specification) and present the results in Figure 3. These estimates are consistent with our other results. For cold temperatures, we again find no evidence of differential pre-treatment trends in the cold-mortality relationship, and no evidence of a treatment effect of CHC establishment. Indeed, none of the 24 coefficient estimates are statistically different from zero. For hot temperatures, we also find no evidence of differential pre-treatment trends in the heat-mortality relationship: none of the eight pre-treatment coefficients are statistically different from zero. The effect of CHCs on the heat-mortality relationship emerges shortly after CHC establishment: the first statistically significant decline in the heat-mortally relationship comes in the third year after establishment $(t=2)$. In total, all 16 of the post-treatment estimates are negative and 11 are statistically significant at the $5 \%$ level.

In summary, these estimates indicate that increased access to community health centers led to a decline in the relationship between heat and mortality. We find no evidence that access to CHCs mitigates the cold-mortality relationship, though our estimates cannot rule out impacts of economically important magnitude.

Why could it be that the heat-mortality relationship is affected by $\mathrm{CHC}$ access while the cold-mortality relationship is not? Truly understanding why this might be the case requires a thorough understanding of the mechanisms that drive each relationship. In many ways, the specific channels through which ambient temperatures affect mortality remain. Getting into this black box is particularly difficult with vital statistics data given that information on the ultimate cause of death may not reflect the initial circumstances that set off the chain of events leading to death, though clues can be inferred from some prior research. For example, White (2017) finds that hot temperatures lead to increases in emergency department visits in the very short term, likely reflecting acute impacts of exposure to high temperatures. Meanwhile, increases in emergency department use due to cold weather take weeks to materialize for essentially all disease categories. The dynamics suggest that the health effects of cold weather are primarily due to changes in infectious disease activity, even when the observed diagnosis is for another category. ${ }^{25}$

If CHCs are effective at improving population health in areas associated with acute health events and but are ineffective at limiting the spread of infectious disease, then this may provide a partial explanation for the differential impacts of CHCs on the cold- and heat-mortality relationships. In fact, Bailey and Goodman-Bacon (2015) find that CHCs most substantially improved outcomes related to cardiovascular and cerebrovascular diseases

\footnotetext{
${ }^{25}$ This interpretation is further supported by the finding that the disease category most strongly affected by a wide margin is respiratory illness (e.g., pneumonia and influenza).
} 
(which are in turn associated with acute health events such as heart attacks and strokes) and were less impactful in addressing infectious diseases. In other words, it may have been the case that CHCs did not reduce mortality once an acute episode occurred (which is expected given than CHCs provided no emergency or acute-care services), but were effective at improving the population's health stock in a manner relevant to diseases affected by heat.

In the following section on Southern hospital desegregation, we consider a change in access to to a very different avenue of health care (hospitals) and a very specific population (post-neonatal infants). Almond et al. (2006) showed that increased access to such care was particularly important for treating infectious diseases among this population. We will show that cold temperatures lead to negative outcomes from exactly these disease types among this same population. As such, this is a setting in which it is at least plausible that increased access to health care may have mitigated the cold-mortality relationship.

\section{Part 2: Southern Hospital Desegregation}

\subsection{Background}

Through the first half of the twentieth century and into the early-1960s, hospitals in the Southern US were highly segregated. The fact that segregation was so prevalent and persistent well into the 1960s was largely a function of the 1946 Hospital Survey and Construction Act - known as the Hill-Burton Act - which provided federal funding for hospital construction. The Hill-Burton Act explicitly allowed for funded hospitals to provide "separate but equal" health care services on the basis of race. This provision remained in force even after the 1954 Brown vs. Board of Education decision that segregation in public education was unconstitutional. Segregation typically entailed a separate hospital building, wing or floor for non-white patients. "Negro wards" were typically sub-standard facilities offering sub-standard care. These facilities were often over-crowded and potential patients would be turned away if the ward was at capacity, even if there were empty beds elsewhere in the hospital. Hospital segregation persisted largely unchecked in the Southern US until at least 1963.

In November 1963, the Fourth Circuit Court of Appeals ruled that the "separate but equal" clause of the Hill-Burton legislation was unconstitutional, disallowing segregated hospitals from receiving new construction funds. This decision did not immediately affect most existing hospitals however, as it only impacted the allocation and disbursement of federal funds for hospital construction. The passage of the Civil Rights Act in July 1964 prohibited segregation in any institution receiving federal funds. This resulted in the desegregation of 
some hospitals, but many remained segregated in the years that followed.

The most important event driving full hospital desegregation was likely the implementation of the Medicare program in July 1966. Eligibility for Medicare reimbursement required a complete end to racial discrimination within hospitals, providing a powerful financial incentive for all hospitals to desegregate. While determining the date of desegregation in all hospitals is a difficult (if not impossible) task, the data on hospital desegregation status by county in Mississippi utilized by Almond et al. (2006) provides some evidence. Almond et al. (2006) find that the first full year in which any county in Mississippi had a desegregated hospital was 1967, and desegregation continued in Mississippi through 1970. In our analysis, we require a single date for desegregation that will apply to all Southern states. We assign 1966 as the first year of desegregation, since this was the year in which the most powerful incentive to desegregate was enacted and the available evidence indicates that many hospitals desegregated during this year.

How would have desegregation affected mortality? Desegregation would have had the largest mortality impacts on potentially fatal illnesses for which effective in-hospital treatments were available. Almond et al. (2006) tailor their analysis to a specific population where this was highly likely: post-neonatal infants (1-12 months after birth). We follow their lead and focus on the same population. Many post-neonatal deaths in this period were due to the contraction of infectious diseases leading to pneumonia and gastroenteritis. Deaths due to these conditions could be avoided with timely medical treatment. Prior to desegregation, the gap in access to timely medical treatment for these conditions was readily apparent in the vital statistics data: Figure A1 reveals that the post-neonatal mortality rate for pneumonia/influenza and gastroenteritis was over four times larger for non-whites compared to whites in the pre-desegregation period. This gap rapidly collapsed once desegregation began in earnest.

How might desegregation have affected the relationship between temperature and mortality? If exposure to extreme temperatures encourages the onset of the types of diseases that desegregation prevented, then it is plausible that desegregation could have substantially altered this relationship. Prior research suggests this is likely the case. For example, using recent data on emergency department visits in California, White (2017) finds that cold temperatures lead to large increases in both digestive diseases (e.g., gastroenteritis) and respiratory diseases (e.g., pneumonia), particularly among children. Using our data, we will show that cold temperatures were a strong driver of post-neonatal mortality, particularly for non-whites prior to desegregation. As such, it is likely that Southern hospital desegregation would have mitigated the relationship between cold temperatures and non-white post-neonatal mortality. 


\subsection{Empirical Framework}

In estimating the effects of desegregation, note that Almond et al. (2006) employ two strategies. The first strategy simply compares mortality among non-whites and whites in Southern states, before and after desegregation occurred in 1966. The second strategy is a more rigorous approach that utilizes the actual year of desegregation by hospital, but confines the analysis to Mississippi where the necessary data is available. Our analysis builds off of the first strategy because we need to simultaneously estimate the effects of temperature, which requires broad geographic coverage and sufficient variation in weather within a given time period. Given that Almond et al. (2006) find very similar results with the two strategies, we are confident that our approach primarily captures the causal effects of desegregation. That being said, we acknowledge that to a small extent our estimates may pick up other factors that contributed to the reduction in the racial gap in post-neonatal mortality in Southern states in the 1960s to 1970 s. As such, our estimates in this section should be considered an upper bound, and we proceed with this caveat in mind.

\subsubsection{Replication Model}

Our analysis of Southern hospital desegregation proceeds in a similar manner to our analysis of CHCs. We begin with a "replication" model that simultaneously estimates the effects of hospital desegregation and temperature on post-neonatal mortality in a single econometric framework. Note that while estimating the effects of desegregation on post-neonatal mortality is a replication of results from Almond et al. (2006), we are aware of no other studies that estimate the effects of temperature on post-neonatal mortality. Our replication model is described below.

$$
\begin{aligned}
\text { PNMR }_{r s y m} & =\gamma\left(\mathrm{NW}_{r} \times \operatorname{Deseg}_{y}^{t \geq 0}\right)+\pi \operatorname{Temp}_{\text {sym }} \\
& +\mu \operatorname{LowPrec}_{s m y}+\rho \operatorname{HighPrec}_{\text {smy }}+\delta_{r s m}+\delta_{s y}+\varepsilon_{r s y m}
\end{aligned}
$$

In this model, $\mathrm{PNMR}_{\text {rsym }}$ is the post-neonatal mortality rate (per 100,000 births) for race $r$, in state $s$, year $y$ and month $m$. An important distinction between this model and our model for CHCs is that here the unit of observation is the race-by-location-by-time, rather than just location-by-time as in the $\mathrm{CHC}$ model. Race in defined as either white or non-white, although in Southern states in this time period the non-white category is overwhelmingly comprised of African Americans. The sample in this model is limited to 
Southern states. ${ }^{26}$

Our estimates of the effects of desegregation on mortality are derived from a simple DiD model in which we compare non-whites and whites, before and after desegregation. Motivation for this approach can be seen easily in the raw data in Figure A1. The coefficient of interest is $\gamma$, where $\mathrm{NW}_{r}$ is an indicator for non-white and $\operatorname{Deseg}_{y}^{t \geq 0}$ is an indicator for years 1966 and later $(t=0$ is 1966). If we were not interested in simultaneously estimating the effects of temperature on mortality, this model could be aggregated to the race-by-time level. Estimating temperature effects requires geographical variation, however, and thus we disaggregate to the state level. ${ }^{27}$

$\pi$ is the coefficient of interest for the effects of temperature. In this simple model, $\pi$ represents the average effect of temperature across white and non-white populations. In

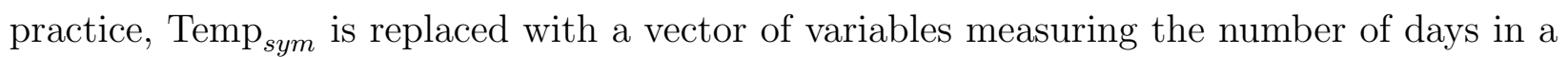
specified temperature range. Because Southern states are warmer on average than the rest of the US, we use the number of days $<50^{\circ} \mathrm{F}$ to represent cold temperatures. ${ }^{28}$ Analogous to the CHC models, LowPrec cym $_{\text {and }}$ HighPrec cym $_{\text {are }}$ precipitation controls indicating monthly precipitation was below the 25 th percentile or above the 75 th percentile of the state-month distribution respectively.

Identification of $\gamma$ in a difference-in-differences framework requires controlling for unobserved time-invariant differences across race, and unobserved race-invariant differences over time. This is accomplished through race-state-month fixed effects $\left(\delta_{r s m}\right)$ and state-year fixed effects $\left(\delta_{s y}\right)$. These controls are specified to facilitate causal identification of $\pi$ as well; in particular, the race-state-month fixed effects control for differences in average temperature and mortality across states, and allow seasonality to vary across both states and races. The state-year fixed effects obviate the need for any additional state-level annually-varying covariates.

Standard errors are two-way clustered at the state and year-month levels in our main specifications. Because there are only 10 states in the Southern US, it is a potential concern that the standard errors are understated due to too few clusters (though two-way clustering alleviates this concern to some extent). As such, we estimate additional models in which we

\footnotetext{
${ }^{26}$ Following Chay et al. (2009), we define the "South" to include Alabama, Arkansas, Florida, Georgia, Louisiana, Mississippi, North Carolina, South Carolina, Tennessee, and Virginia. The results are very similar when we define the South as the Southern Census Region, which additionally includes Delaware, D.C., Kentucky, Maryland, Oklahoma, Texas, and West Virginia.

${ }^{27}$ In principle the model could be estimated at the county level, however because the denominator in the outcome is the annual number of births, the outcome is undefined for some counties in which there were zero births for a particular race-year. We have estimated the model at the county level, omitting small counties in which the outcome is undefined, and find very similar results. These estimates are available upon request.

${ }^{28}$ The average number of days $<50$ in the South is approximately equal to the number of days $<40$ for the entire US.
} 
use two-way wild-cluster bootstrapped p-values (Cameron et al., 2008). All regressions are weighted by the 1960 state-by-race population.

\subsubsection{Interaction Model}

The model used to estimate the interaction between desegregation and temperature exposure is very similar in spirit to the interaction model for CHCs, and is described below:

$$
\begin{aligned}
\text { PNMR }_{\text {sym }} & =\phi\left(\mathrm{NW}_{r} \times \operatorname{Deseg}_{y}^{t \geq 0} \times \operatorname{Temp}_{\text {sym }}\right)+\gamma\left(\mathrm{NW}_{r} \times \operatorname{Deseg}_{y}^{t \geq 0}\right)+\pi_{1} \text { Temp }_{\text {sym }} \\
& +\pi_{2}\left(\operatorname{Temp}_{\text {sym }} \times \mathrm{NW}_{r}\right)+\mathrm{Temp}_{\text {sym }} \times \delta_{y}+\kappa\left(\operatorname{Temp}_{\text {smy }} \times A C_{r s y}\right) \\
& +\mu \text { LowPrec }_{\text {smy }}+\rho \operatorname{HighPrec}_{\text {smy }}+\delta_{\text {rsm }}+\delta_{\text {sy }}+\varepsilon_{\text {rsym }}
\end{aligned}
$$

This is essentially a triple-differences model in which the coefficient of interest $(\phi)$ is on the three-way interaction. We interpret $\phi$ as the effect of desegregation on the temperaturePNMR relationship. Similar to our model for CHCs, we are again careful to control for fixed differences in the effects of temperature across treated and untreated groups. In this case, race defines the treatment group, and thus Temp $\mathrm{Tym}_{\text {sy }} \times \mathrm{NW}_{r}$ allows for these differences. We also allow for the effect of temperature to vary over time $\left(\operatorname{Temp}_{\text {sym }} \times \delta_{y}\right)$ and across $\mathrm{AC}$ penetration rates $\left(\mathrm{Temp}_{s m y} \times A C_{r s y}\right)$ in a manner that is fixed across non-whites and whites. The precipitation controls and fixed effects are the same as in the replication model.

Similar to our model for CHCs, we also expand this basic framework to include more temperature bins and we estimate event-study versions of the model to assess dynamic effects and evaluate whether differential trends in the temperature-mortality relationship across races could be driving the results. See Equation (6) in the Appendix for specification details.

It is possible that other factors coinciding with Southern hospital desegregation could have differentially affected the temperature-mortality relationship among non-whites and whites. To the extent that these factors were similar across Southern and non-Southern states, it is possible to difference out these factors by including all states in the regression and including an indicator for Southern states (and the relevant interactions). This quadruple-differences approach is taken as an alternative specification, and the model is described in Equation (7) in the Appendix. 


\subsection{Results}

\subsubsection{Replication Model}

The results of the replication model are presented in Table 4. Column 1 presents a DiD estimate of the effect of desegregation; the estimate implies that desegregation decreased the non-white post-neonatal mortality rate by approximately 66 per 100,000 births. Relative to the pre-desegregation mean non-white post-neonatal mortality rate of 164 , this represents a $40 \%$ decline. The magnitude of this estimate is quite comparable to the estimates from both empirical strategies employed by Almond et al. (2006). Column 2 presents estimates for the effects of $<50^{\circ} \mathrm{F}$ and $>80^{\circ} \mathrm{F}$ days on the post-neonatal mortality rate (the average effect across non-whites and whites). The estimates indicate that both hot and cold temperature shocks lead to significant increases in post-neonatal mortality, though the estimates for cold are substantially larger.

Column 3 reports estimates from the model which includes both the effects of desegregation and temperature in a single regression, and the coefficient estimates are virtually unchanged, supporting the notion that these two treatments are independent. Columns 4 and 5 present binned event study estimates for the effects of desegregation. These estimates indicate no evidence of differential pre-desegregation trends in mortality between non-whites and whites, and a treatment effect that grows over time. This is further supported in Figure 4, which plots an event study for the effects of desegregation on mortality and estimates from four 10 -degree temperature bins from $<50^{\circ} \mathrm{F}$ to $>80^{\circ} \mathrm{F}\left(60-70^{\circ} \mathrm{F}\right.$ is omitted).

The effects of temperature we have presented thus far represent the average effect across white and non-white individuals over the entire sample period (1959-1988), and as such these estimates mask considerable heterogeneity. Figure 5 plots the effects of temperature in the period prior to desegregation (1959-1965) separately for non-whites and whites, and by allcause deaths and deaths related to pneumonia/influenza and gastroenteritis ("PI/Gastro"). ${ }^{29}$ This figure reveals a large gap in the effects of cold temperature on mortality in the period prior to desegregation between non-whites (Coef. $=2.6$ ) and whites (Coef. $=0.7$ ); we seek to test whether hospital desegregation was successful in shrinking this gap. Notably, PI/Gastro deaths account for $67 \%$ of all cold-induced post-neonatal deaths among non-whites in this period. This fits well with the Almond et al. (2006) findings that PI/Gastro deaths accounted for much of the decline in post-neonatal mortality due to desegregation. ${ }^{30}$ Also note that the

\footnotetext{
${ }^{29}$ Separate estimates for whites and non-whites are calculated by including an interaction between temperature and race $\left(\operatorname{Temp}_{\text {sym }} \times \mathrm{NW}_{r}\right)$.

${ }^{30} \mathrm{We}$ find similar results as well. If we re-estimate the coefficient from Column 1 of Table 4 with PI/Gastro deaths as the outcome, the estimate equals 49.1 . This represents $74 \%$ of the decline in all-cause post-neonatal mortality.
} 
estimated effects of hot temperatures are small and insignificant for both non-whites (Coef. $=0.6$ ) and whites (Coef. $=0.0)$, making it unlikely that any effects of desegregation on the heat-mortality relationship will be discernible in this context.

\subsubsection{Interaction Model}

Table 5 presents the coefficient estimates for the interaction between desegregation and extreme temperature. Column 1 includes the minimum controls necessary for identifying the interaction effect $($ Temp $\times$ NW allows for fixed differences in the effects of temperature between treatment groups; Temp $\times \delta_{y}$ allows for the effects of temperature to vary over time). Column 2 allows the effects of temperature to differ by AC penetration rates. Column 3 provides a specification check by allowing time-invariant differences in the effects of temperature by state and race, though identification does not require that we allow the effects of temperature to vary by geography since the treatment group is defined by race rather than location. $^{31}$

Panel A reports the results from the model with a single post-desegregation indicator (rather than an event study). The coefficient estimate on $\mathrm{NW} \times \operatorname{Deseg}^{t \geq 0} \times \mathrm{Temp}^{<50}$ is large in magnitude, negative, and highly significant across all three specifications. In Column 2 (our preferred specification), the coefficient estimate is approximately -2.6. This point estimate is very close to the estimated magnitude of the effect of cold on non-white PNMR in the pre-desegregation period (also estimated to equal 2.6, coincidentally), suggesting that effectively all of the mortality effects of cold on post-neonatal infants were eliminated by the improved access to hospital services provided by desegregation. However, the confidence intervals are fairly wide on both the interaction (95\% CI: -4.0 to -1.3$)$ and the pre-desegregation effects of temperature (95\% CI: 1.1 to 4.1), so we cannot rule out much smaller mitigation effects. For example, if we take an extreme case and use the lower-bound interaction effect and the upper-bound pre-desegregation temperature effect, the estimates imply mitigation equal to $32 \%$. In any case, the estimates causally demonstrate that hospital desegregation substantially mitigated the relationship between cold temperatures and non-white post-neonatal mortality in Southern US states. We find no evidence that hospital desegregation mitigated the relationship between hot temperatures and mortality for this group, though in comparison to cold temperatures there was little to mitigate in the first place.

Panel B of Table 5 reports estimates from a binned event study approach. The estimates

\footnotetext{
${ }^{31}$ This is different in spirit from Column 3 in Table 3. In Table 3, the specification in Column 3 replaced Temp $\times$ Treated with controls intended to serve the same purpose at a finer level $\left(\right.$ Temp $\left.\times \delta_{c}\right)$. In Table 5 , the additional controls in Column 3 are not replacing any of the previously-included controls.
} 
on the pre-desegregation term $\left(\mathrm{NW} \times \operatorname{Deseg}^{t \geq 0} \times \mathrm{Temp}^{<50}\right)$ are negative and marginally significant; these negative effects imply that there was a slight positive trend in the effects of cold on mortality for non-whites relative to whites prior to desegregation. As such, it is unlikely that the negative impacts we are estimate are a result of these differential trends. This is more easily visualized in the annual event study presented in Figure 6. Here, an upward trend in the gap between the effects of cold on non-white and white PNMR prior to desegregation is visually apparent. This trend reverses and becomes negative immediately following desegregation, supporting the idea that the observed declines in cold-related mortality are largely attributable to desegregation. There is no evidence of differential pre-desegregation trends in the effects of hot temperature, nor is there evidence of a post-desegregation treatment effect.

Estimates from a quadruple-differences approach are presented in Table A5. The estimated magnitudes are similar (though slightly smaller) to those from the main specification. These results confirm that the collapse in the cold-mortality relationship among non-whites following desegregation was indeed concentrated among the Southern states in which desegregation had the largest impacts. Finally, in Table A6, we present estimates from the main (triple-differences) specification for all-infant and all-age mortality outcomes. These estimates are similar in character to our main results for PNMR, but suggest that the benefits to non-whites of hospital desegregation were not limited to post-neonatal infants. ${ }^{32}$

This analysis provides a particularly stark example of how access to health care can mitigate environmental damages. The large ameliorative impacts identified here for the coldmortality relationship are attributable to two characteristics of the setting. First, the policy intervention represents an extremely large change in access to health care for the group that we study. Second, the intervention (increased access to hospital services) is highly relevant for precisely the same population (infants 1-12 months old) and diseases (pneumonia/influenza and gastroenteritis) that the environmental shock (cold temperatures) affected.

\section{Discussion and Conclusion}

This paper uses a causal framework to test whether access to each of two distinct dimensions of health care (primary care and hospital care) mitigates damages from each of two types of environmental exposure (cold and hot temperatures). In the first setting, we find that the county-level establishment of Community Health Centers mitigated the harmful relationship between high temperatures and general mortality rates by approximately $15 \%$, and we find

\footnotetext{
${ }^{32}$ The all-age estimates suggest that desegregation mitigated the relationship between cold temperatures and all-age mortality by approximately $39 \%$.
} 
no statistically significant evidence showing that CHCs affected cold-induced mortality. In the second setting, we find that Southern hospital desegregation completely diminished the relationship between cold temperatures and non-white post-neonatal mortality rates.

This paper successfully identifies health care as a causal source of heterogeneity in environmental damages. The desegregation analysis illustrates this point most clearly. Prior to desegregation there existed a large gap between non-whites and whites in the mortality effects of exposure to cold temperatures. Our results imply that differential access to health care prior to desegregation explains this entire gap. The results of the $\mathrm{CHC}$ analysis are more subtle in this respect, but they do imply that differential access to primary care explains a meaningful share of the variation in the mortality effects of hot temperatures across locations and populations.

Taken together, the results from the two parts of this paper show that the setting matters tremendously in considering whether and how access to health care can mitigate environmental damages. For access to health care to matter, it must be that the specific dimension of health care considered is effective at addressing the types of ailments triggered by the environmental shock of interest. Again, the desegregation analysis makes this point most clearly: desegregation provided access to timely and effective treatments for pneumonia/influenza and gastroenteritis, which are precisely the same conditions through which exposure to cold temperatures lead to death in the studied population of post-neonatal infants.

What do our results imply for climate change? The results of the $\mathrm{CHC}$ analysis suggest that improved access to primary care can limit the health damages associated with higher temperatures. Thus, our findings suggest that improving access to primary care services may be one effective means of adapting to climate change. The results of the paper as a whole speak to this question more broadly. Improving access to health care can be a tool for climate change adaptation, but its effectiveness depends on our ability to precisely target the health outcomes that we expect to be affected by a changing climate. In order to develop effective policies for targeted health interventions, a necessary step for future research will be to delve deeper into the black box of the relationship between temperature and health. Precisely understanding the pathways through which ambient temperatures affect health will allow health care interventions to be effectively tailored to a world with a warmer climate. 


\section{References}

Adhvaryu, Achyuta, Anant Nyshadham, Teresa Molina, and Jorge Tamayo, "Helping Children Catch Up: Early Life Shocks and the PROGRESA Experiment," Working Paper 24848, National Bureau of Economic Research July 2018.

Almond, Douglas and Bhashkar Mazumder, "Fetal origins and parental responses," Annu. Rev. Econ., 2013, 5 (1), 37-56.

_, Kenneth Y Chay, and Michael Greenstone, "Civil rights, the war on poverty, and black-white convergence in infant mortality in the rural South and Mississippi," 2006.

Arceo, Eva, Rema Hanna, and Paulina Oliva, "Does the effect of pollution on infant mortality differ between developing and developed countries? Evidence from Mexico City," The Economic Journal, 2016, 126 (591), 257-280.

Bailey, Martha J and Andrew Goodman-Bacon, "The War on Poverty's experiment in public medicine: Community health centers and the mortality of older Americans," American Economic Review, 2015, 105 (3), 1067-1104.

Banerjee, Rakesh and Riddhi Maharaj, "Heat, Infant Mortality and Adaptation: Evidence from India," 2018.

Banzhaf, Spencer, Lala Ma, and Christopher Timmins, "Environmental Justice: The Economics of Race, Place, and Pollution," Journal of Economic Perspectives, 2019, 33 (1), $185-208$.

Barreca, Alan, Karen Clay, Olivier Deschenes, Michael Greenstone, and Joseph S Shapiro, "Adapting to Climate Change: The Remarkable Decline in the US TemperatureMortality Relationship over the Twentieth Century," Journal of Political Economy, 2016, 124 (1), 105-159.

Borusyak, Kirill and Xavier Jaravel, "Revisiting event study designs," Available at SSRN 2826228, 2017.

Burgess, Robin, Olivier Deschenes, Dave Donaldson, and Michael Greenstone, "Weather, climate change and death in India," University of Chicago, 2017.

Cameron, A Colin, Jonah B Gelbach, and Douglas L Miller, "Bootstrap-based improvements for inference with clustered errors," The Review of Economics and Statistics, 2008, $90(3), 414-427$.

_ , _, and _, "Robust inference with multiway clustering," Journal of Business 6 Economic Statistics, 2011, 29 (2), 238-249.

Carleton, Tamma, Michael Delgado, Michael Greenstone, Trevor Houser, Solomon Hsiang, Andrew Hultgren, Amir Jina, Robert E Kopp, Kelly McCusker, Ishan Nath et al., "Valuing the Global Mortality Consequences of Climate Change Accounting for Adaptation Costs and Benefits," 2018. 
Chay, Kenneth Y and Michael Greenstone, "The impact of air pollution on infant mortality: evidence from geographic variation in pollution shocks induced by a recession," The quarterly journal of economics, 2003, 118 (3), 1121-1167.

_, Jonathan Guryan, and Bhashkar Mazumder, "Birth cohort and the black-white achievement gap: The roles of access and health soon after birth," Technical Report, National Bureau of Economic Research 2009.

Cohen, François and Antoine Dechezleprêtre, "Mortality inequality, temperature and public health provision: evidence from Mexico," 2018.

Crump, Richard K, V Joseph Hotz, Guido W Imbens, and Oscar A Mitnik, "Dealing with limited overlap in estimation of average treatment effects," Biometrika, 2009, 96 (1), 187-199.

Currie, Janet and Reed Walker, "Traffic congestion and infant health: Evidence from E-ZPass," American Economic Journal: Applied Economics, 2011, 3 (1), 65-90.

Dell, Melissa, Benjamin F Jones, and Benjamin A Olken, "What Do We Learn from the Weather? The New Climate-Economy Literature," Journal of Economic Literature, 2014, 52 (3), 740-798.

Deschênes, Olivier and Michael Greenstone, "The economic impacts of climate change: evidence from agricultural output and random fluctuations in weather," American Economic Review, 2007, 97 (1), 354-385.

_ and _, "Climate Change, Mortality, and Adaptation: Evidence from Annual Fluctuations in Weather in the US," American Economic Journal: Applied Economics, 2011, pp. $152-185$.

Dillender, Marcus, "Climate Change and Occupational Health: Are There Limits to Our Ability to Adapt?," 2019.

Fetzer, Thiemo, "Can workfare programs moderate violence? Evidence from India," 2014.

Finkelstein, Amy and Robin McKnight, "What did Medicare do? The initial impact of Medicare on mortality and out of pocket medical spending," Journal of public economics, 2008, 92 (7), 1644-1668.

Garg, Teevrat, Maulik Jagnani, and Vis Taraz, "Temperature and human capital in India," 2018.

Goodman-Bacon, Andrew, "Difference-in-differences with variation in treatment timing," Technical Report, National Bureau of Economic Research 2018.

_ , "Public insurance and mortality: evidence from Medicaid implementation," Journal of Political Economy, 2018, 126 (1), 216-262.

Graff Zivin, Joshua and Matthew Neidell, "Environment, Health, and Human Capital," Journal of Economic Literature, 2013, 51 (3), 689-730. 
Gunnsteinsson, Snaebjorn, Achyuta Adhvaryu, Parul Christian, Alain Labrique, Jonathan Sugimoto, Abu Ahmed Shamim, and Keith P West Jr, "Protecting Infants from Natural Disasters: The Case of Vitamin A Supplementation and a Tornado in Bangladesh," 2018.

Heutel, Garth, Nolan H Miller, and David Molitor, "Adaptation and the Mortality Effects of Temperature Across US Climate Regions," Technical Report, National Bureau of Economic Research 2017.

Hornbeck, Richard and Pinar Keskin, "The historically evolving impact of the ogallala aquifer: Agricultural adaptation to groundwater and drought," American Economic Journal: Applied Economics, 2014, 6 (1), 190-219.

Hsiang, Solomon, Paulina Oliva, and Reed Walker, "The Distribution of Environmental Damages," Review of Environmental Economics and Policy, 2019.

Johnson, Rucker C and C Kirabo Jackson, "Reducing Inequality through Dynamic Complementarity: Evidence from Head Start and Public School Spending," American Economic Journal: Economic Policy, 2019.

Karlsson, Martin and Nicolas R Ziebarth, "Population health effects and health-related costs of extreme temperatures: Comprehensive evidence from Germany," Journal of Environmental Economics and Management, 2018, 91, 93-117.

Mullins, Jamie T and Corey White, "Temperature and Mental Health: Evidence from the Spectrum of Mental Health Outcomes," 2018.

Rao, Tanvi, "The Impact of a Community Health Worker Program on Childhood Immunization: Evidence from India's 'ASHA' Workers," SSRN Electronic Journal, 012014.

Rossin-Slater, Maya and Miriam Wüst, "What is the added value of preschool? Longterm impacts and interactions with an infant health intervention," NBER Working Paper No. 22700, IZA Discussion Paper No, 2018, 10254.

Sarsons, Heather, "Rainfall and conflict: A cautionary tale," Journal of development Economics, 2015, 115, 62-72.

Schlenker, Wolfram and Michael J Roberts, "Nonlinear temperature effects indicate severe damages to US crop yields under climate change," Proceedings of the National Academy of Sciences, 2009, 106 (37), 15594-15598.

White, Corey, "The dynamic relationship between temperature and morbidity," Journal of the Association of Environmental and Resource Economists, 2017, 4 (4), 1155-1198. 
Figure 1: Trends in Mortality, Government Health Spending, Medical Innovation, and $\frac{\partial \text { Mortality }}{\partial \operatorname{Temperature}}$

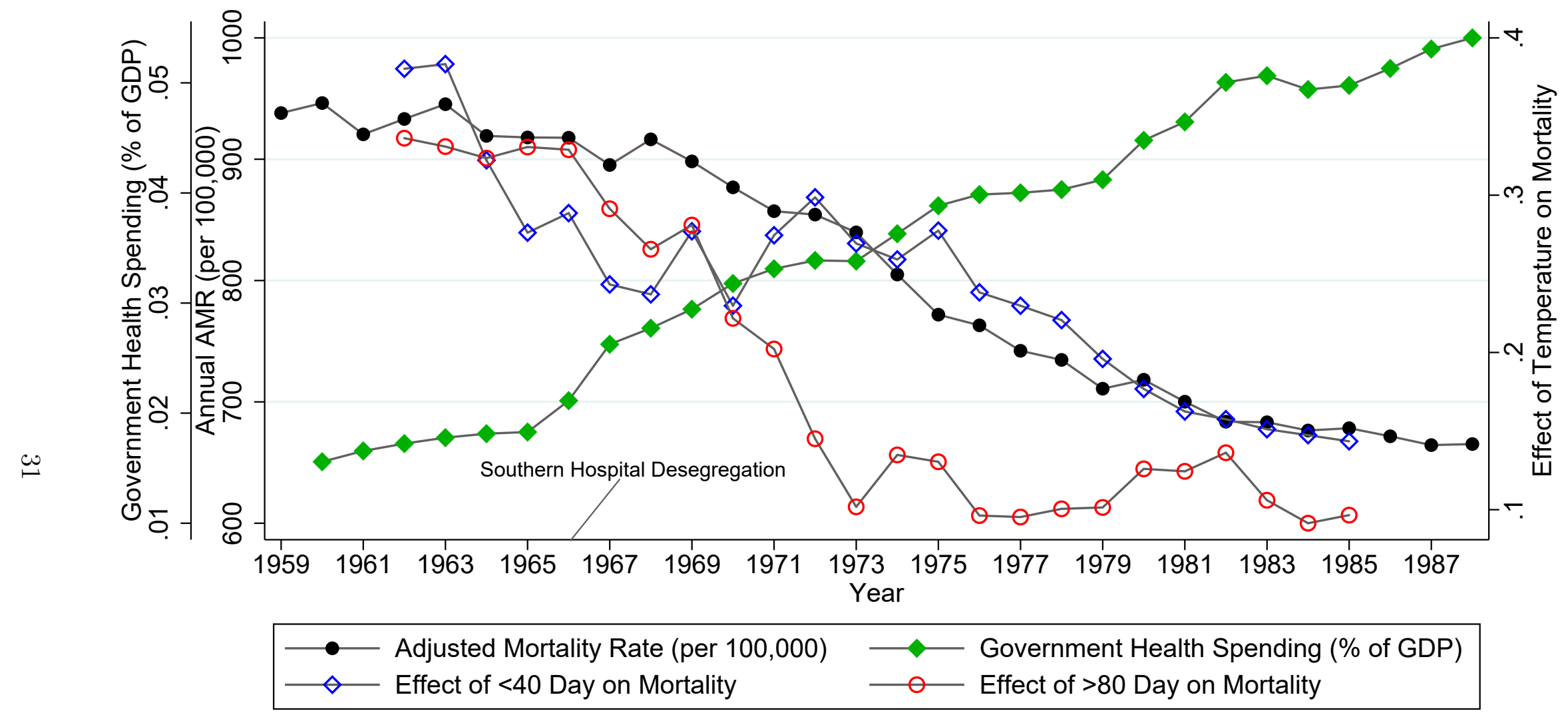

Notes: Coefficient estimates for the effects of temperature and mortality are from models described in Section 3.2.1 with five temperature bins and the sample limited to a 7 year period centered around the year in question. For example, the sample for the point labelled "1962" is 1959-1965. All of the estimates are significant at the $5 \%$ level; interpretation of the magnitudes of similar estiamtes is given in Section 3.3.1. Desegregation is defined as occurring in 1966, when integration became a condition for Medicare reimbursement. Data on government health expenditures are from the National Health Expenditure Accounts, and include government spending on health insurance for the Department of Defense and the Department of Veterans Affairs, CMS programs (Medicaid and Medicare), government public health expenditures (including the CHC program), government health investments, and other programs. The age-adjusted mortality rate is calculated at the annual level for the entire US population. 
Figure 2: Effects of CHC Access and Temperature on Mortality
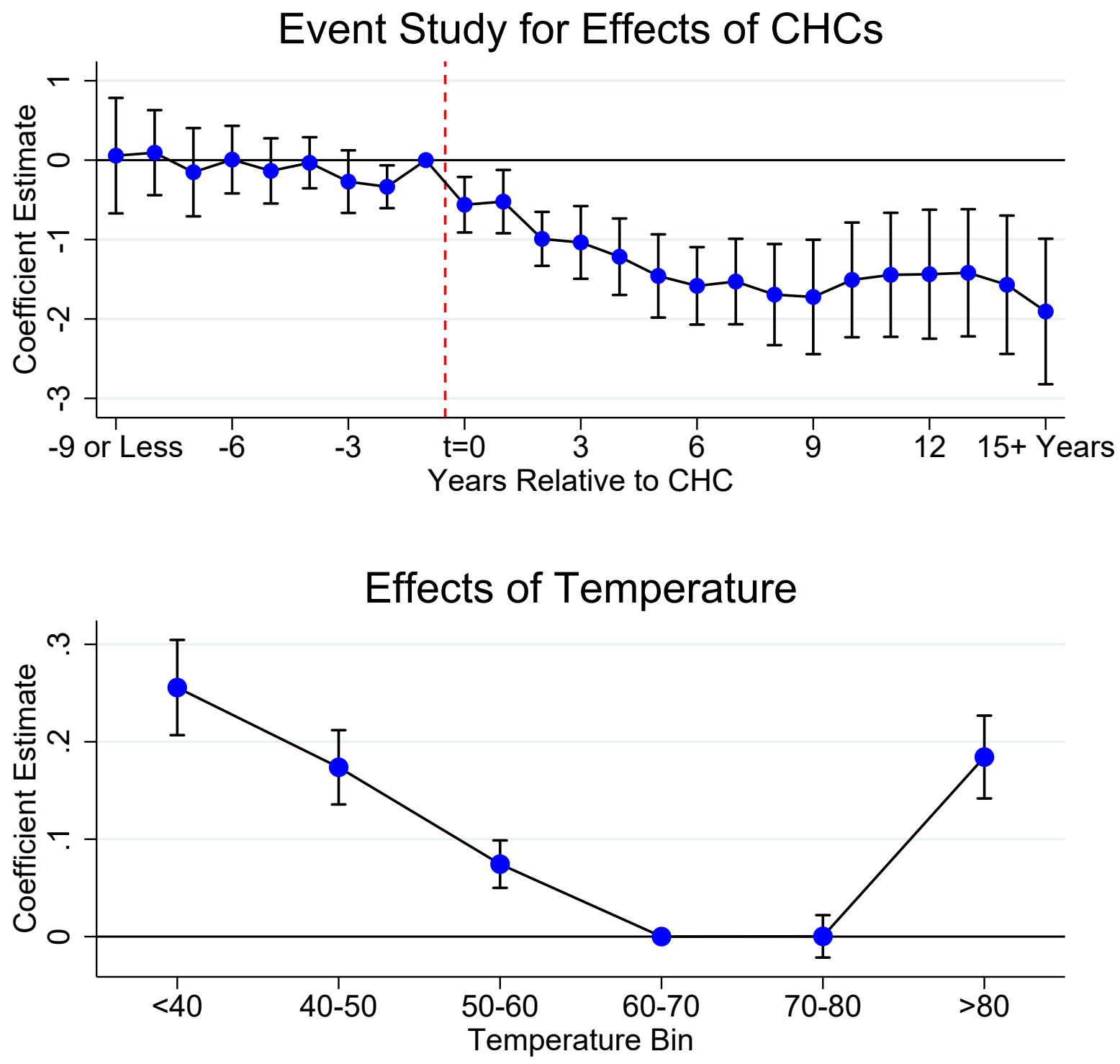

Notes: All estimates in both panels are derived from a single regression. In the event study, period $t=0$ represents the year in which a $\mathrm{CHC}$ was established in a given county. A balanced panel of counties identify all event study coefficients between $t-6$ and $t+14$ (i.e., the same number of counties identify these coefficients). In both figures, bars represent $95 \%$ confidence intervals. 
Figure 3: Event Study for the Effect of CHC Access on $\frac{\partial \text { Mortality }}{\partial \text { Temp }}$

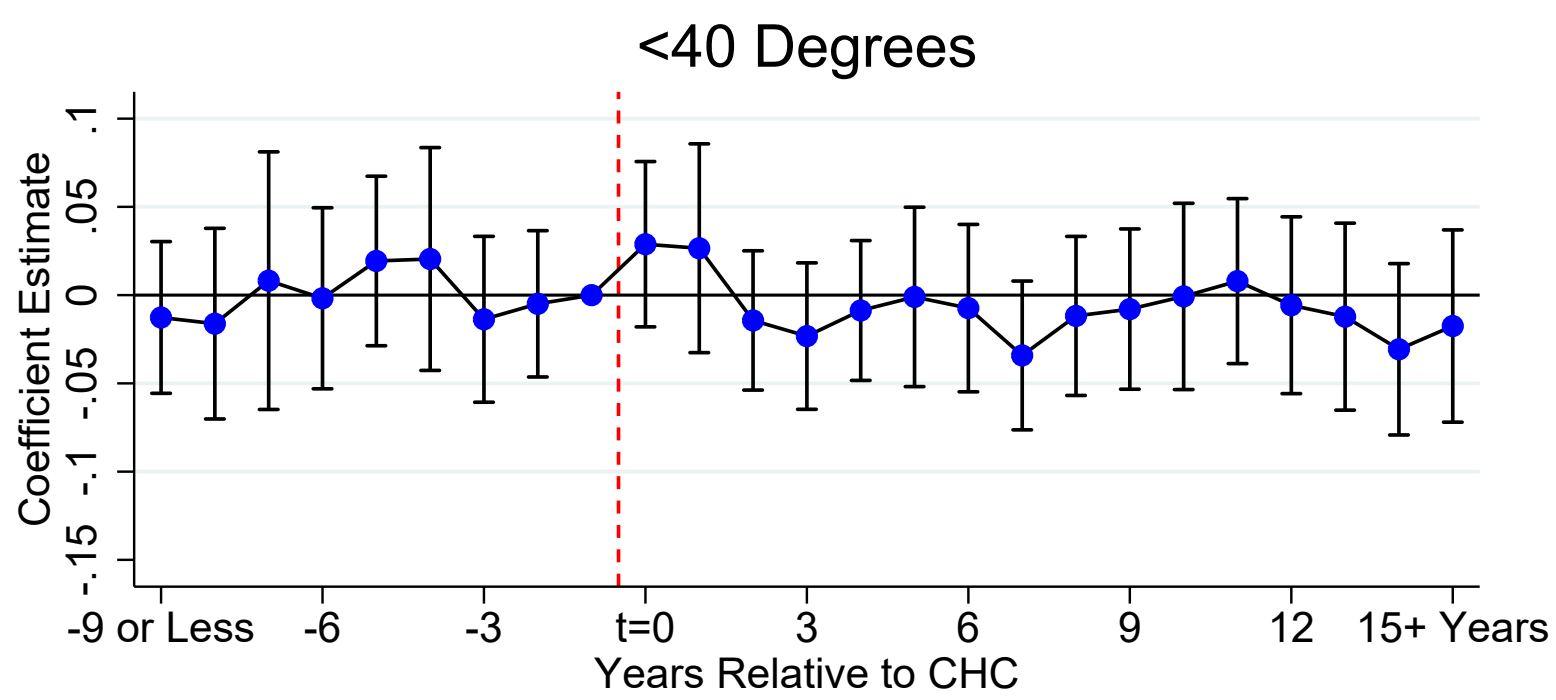

$>80$ Degrees

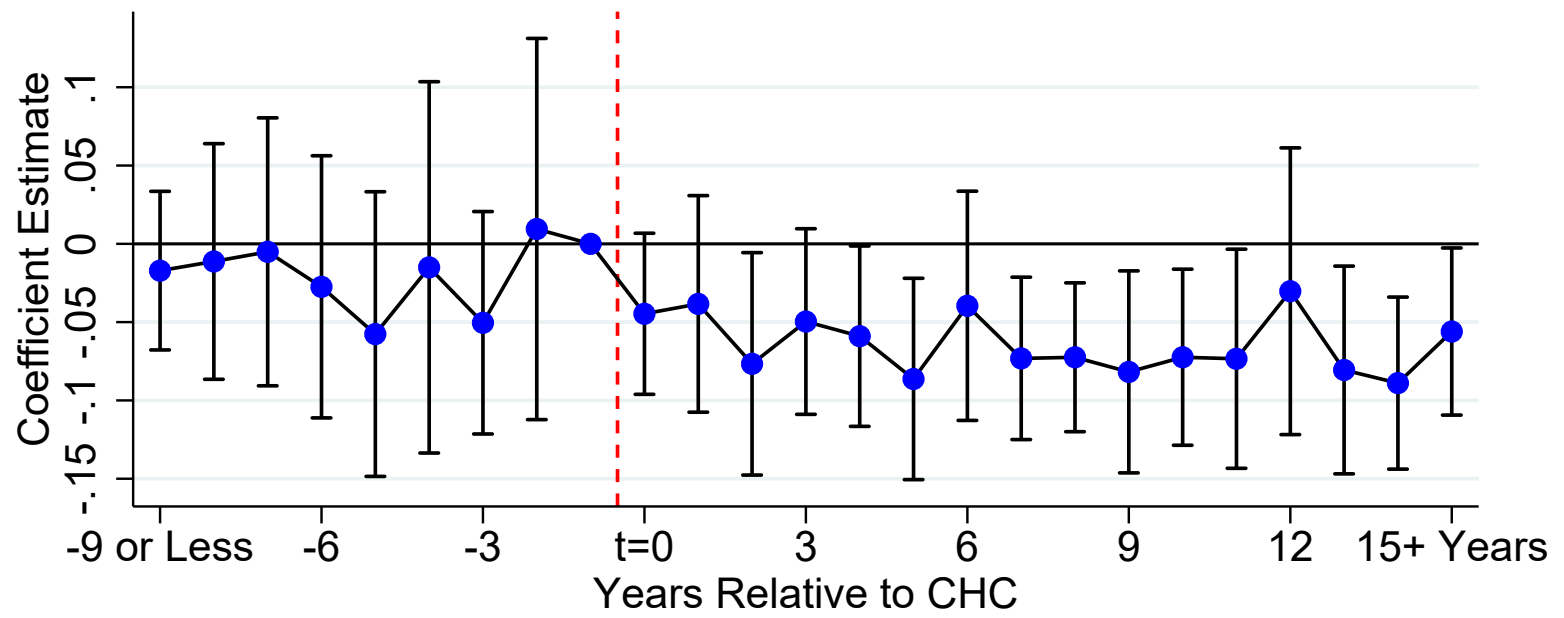

Notes: All estimates in both panels are derived from a single regression. Period $t=0$ represents the first year in which a $\mathrm{CHC}$ was established in a given county. A balanced panel of counties identify all event study coefficients between $t-6$ and $t+14$ (i.e., the same number of counties identify these coefficients). Bars represent $95 \%$ confidence intervals. 
Figure 4: Effects of Desegregation and Temperature on Post-Neonatal Mortality in Southern States

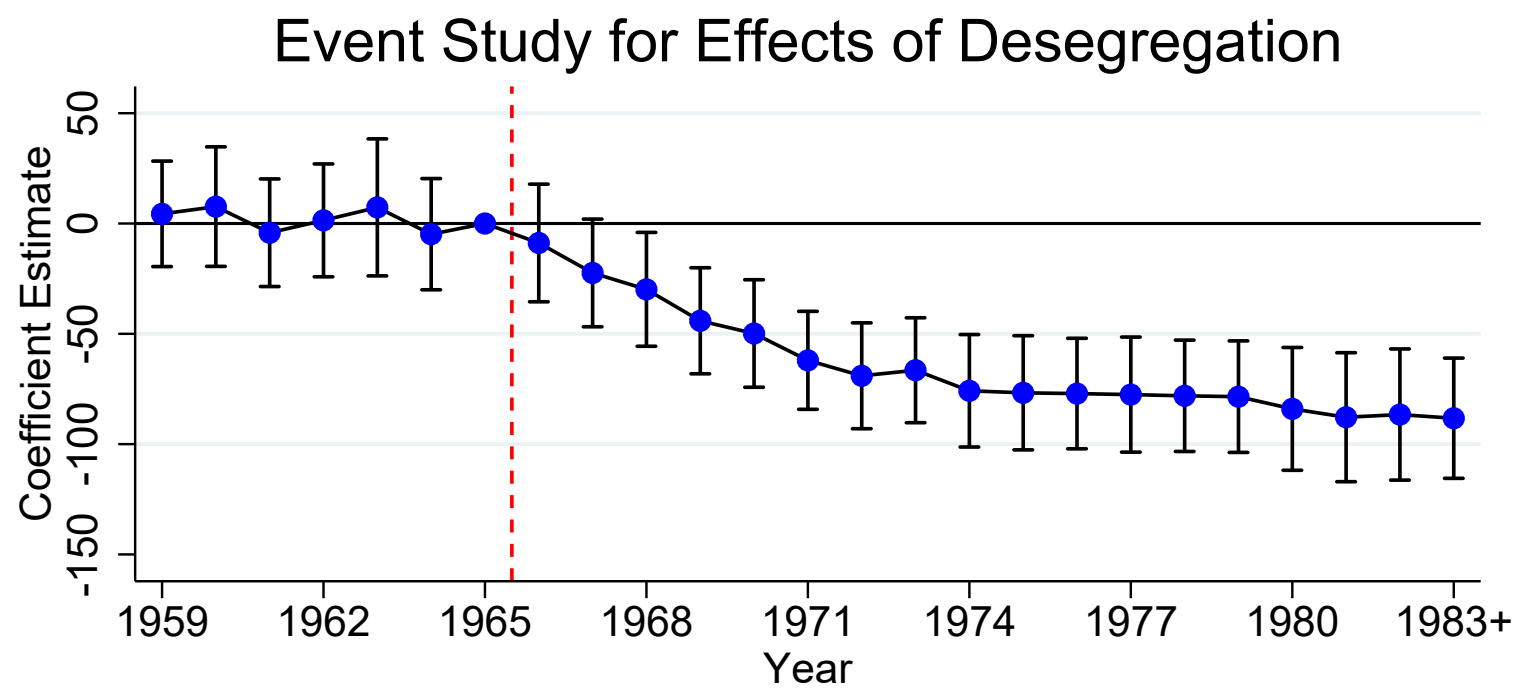

Effects of Temperature

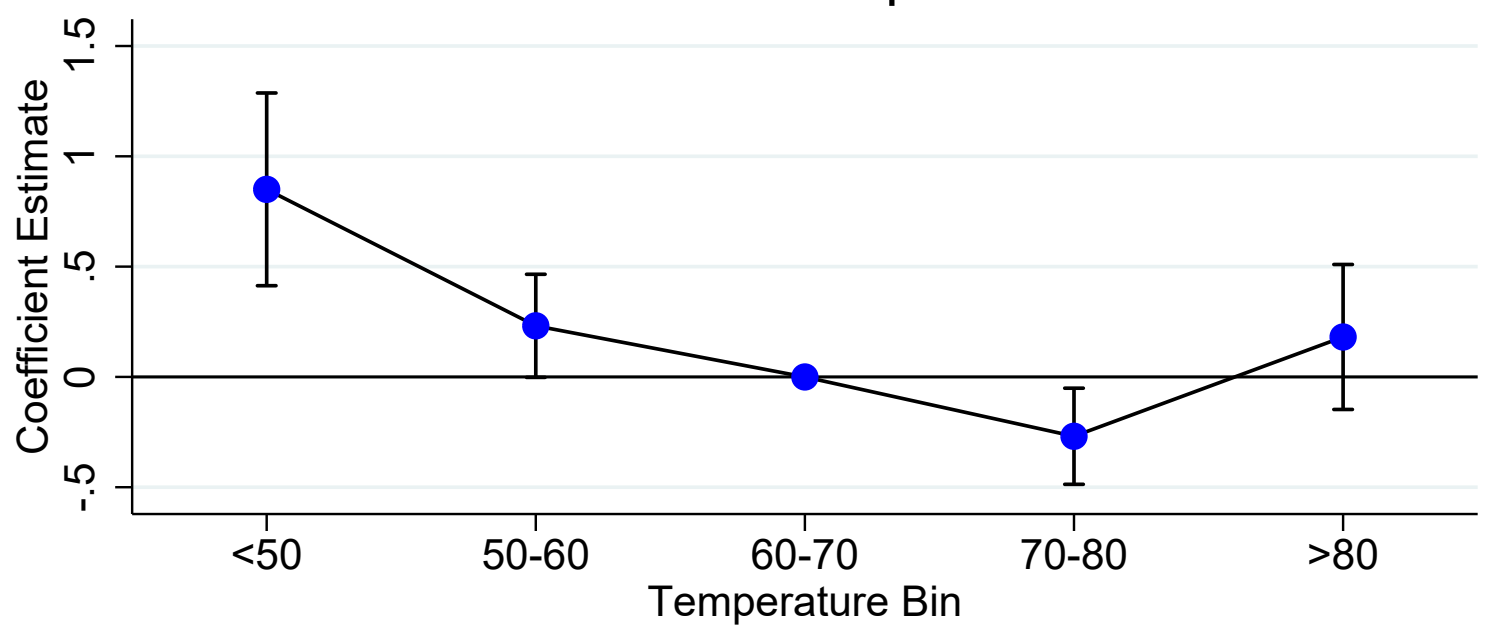

Notes: All estimates in both panels are derived from a single regression. Effects of desegregation represent non-white mortality (relative to white mortality); effects of temperature represent all races. The first year of desegregation $(t=0)$ is set to 1966, and $1965(t=-1)$ is the excluded reference period. In both figures, bars represent $95 \%$ confidence intervals. 
Figure 5: Effects of Temperature on Post-Neonatal Mortality for Non-Whites and Whites in Southern States, Pre-Desegregation (1959-1965)
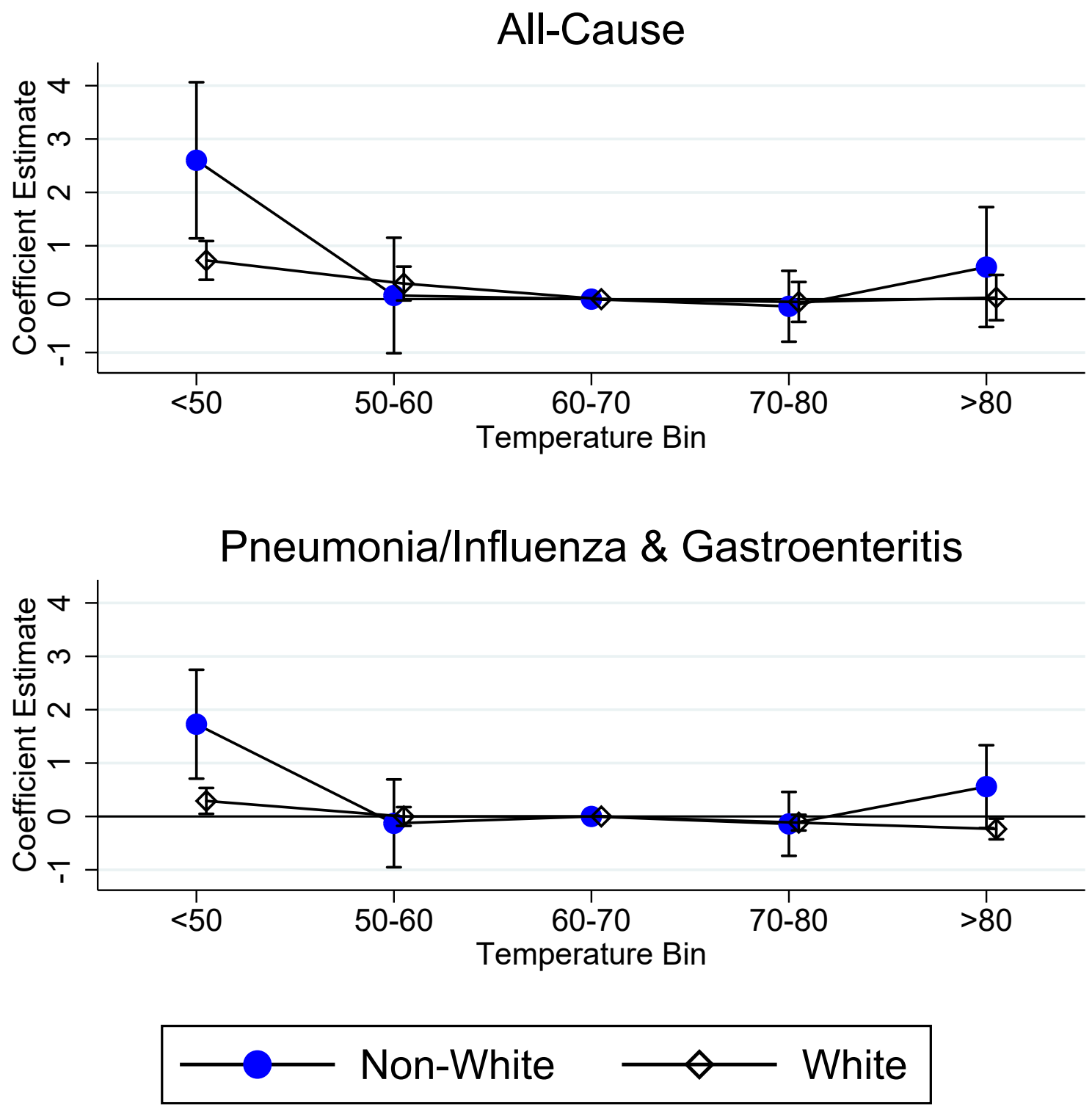

Notes: The sample is limited to Southern states in years 1959-1965. The $<50$ coefficient estimate for nonwhites is 2.60 for all-cause deaths and 1.73 for PI/Gastro deaths. Bars represent $95 \%$ confidence intervals. Each panel presents estimates from a single regression, with race-specific estimates based on interactions between temperature bins and a non-white indicator. 
Figure 6: Event Study for the Effect of Desegregation on $\frac{\partial \mathrm{PNMR}}{\partial \mathrm{Temp}}$ in Southern States

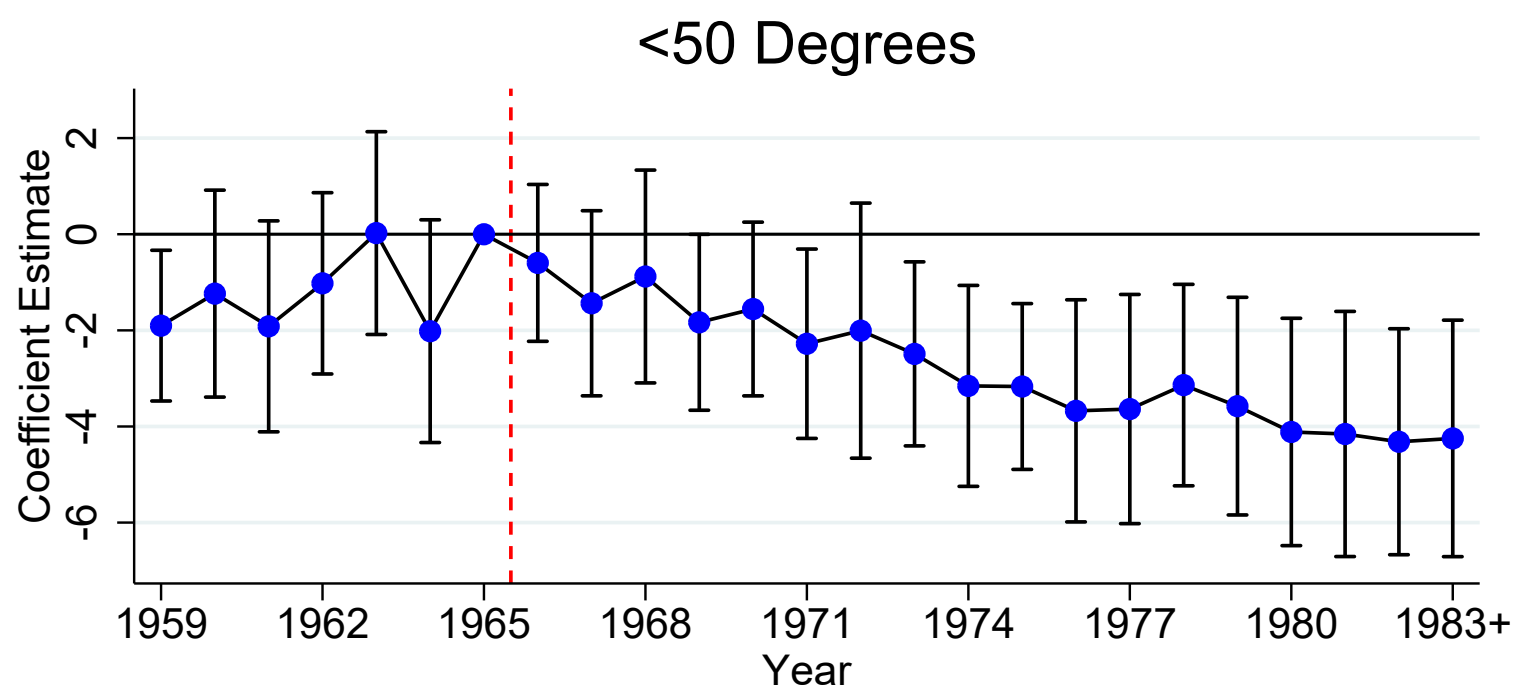

$>80$ Degrees

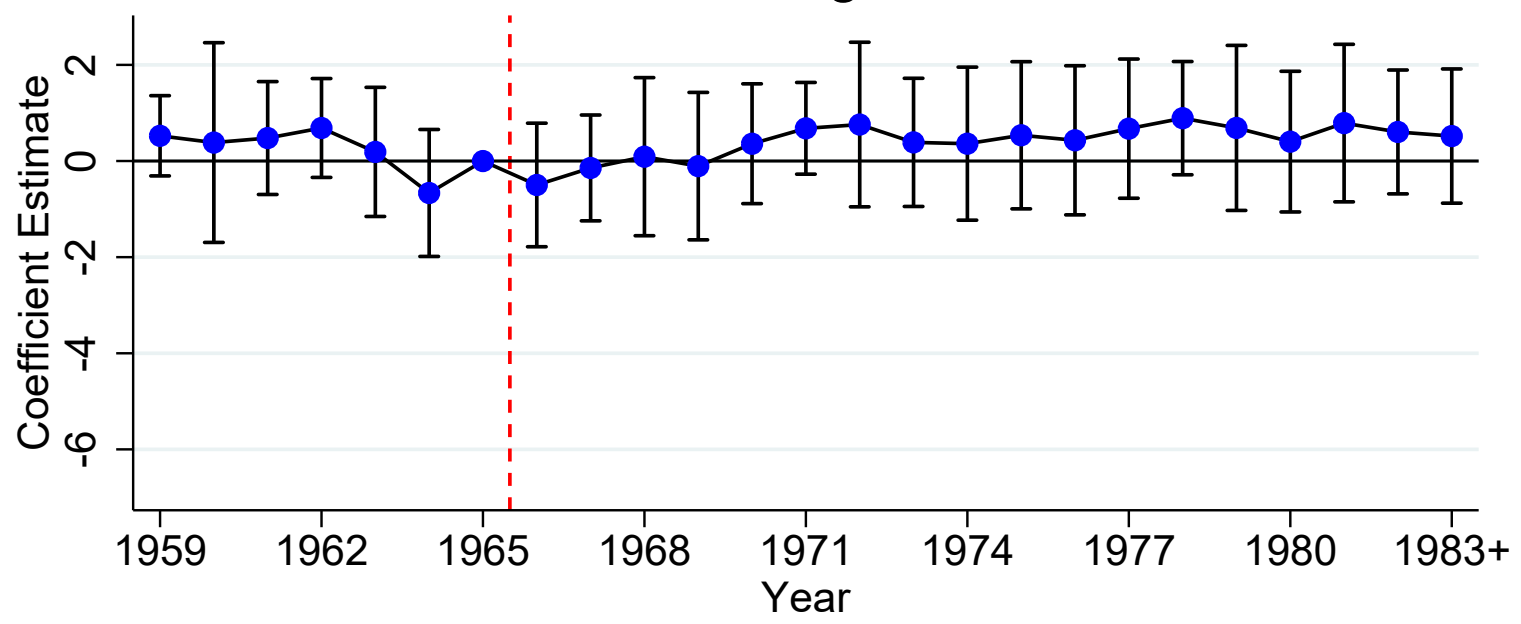

Notes: All estimates in both panels are derived from a single regression. The first year of desegregation $(t=0)$ is set to 1966 , and $1965(t=-1)$ is the excluded reference period. Bars represent $95 \%$ confidence intervals. 
Table 1: Summary Statistics

\begin{tabular}{|c|c|c|c|c|c|c|c|c|}
\hline & \multicolumn{8}{|c|}{ Panel A: CHC Analysis - All US Counties } \\
\hline & \multicolumn{4}{|c|}{ CHC Counties } & \multicolumn{4}{|c|}{ Non-CHC Counties } \\
\hline & \multicolumn{2}{|c|}{ 1959-1965 } & \multicolumn{2}{|c|}{ All Years } & \multicolumn{2}{|c|}{ 1959-1965 } & \multicolumn{2}{|c|}{ All Years } \\
\hline & Mean & S.D. & Mean & S.D. & Mean & S.D. & Mean & S.D. \\
\hline AMR & 81.26 & (11.16) & 70.97 & $(13.25)$ & 76.61 & $(17.44)$ & 67.15 & $(17.42)$ \\
\hline Temperature $\left({ }^{\circ} \mathrm{F}\right)$ & 55.26 & (16.89) & 55.37 & $(16.8)$ & 54.29 & $(17.61)$ & 54.29 & (17.49) \\
\hline Num. Days < $<0$ & 6.56 & $(10.24)$ & 6.42 & $(10.1)$ & 7.41 & (10.67) & 7.29 & $(10.54)$ \\
\hline Num. Days 40-50 & 4.53 & $(5.84)$ & 4.55 & $(5.85)$ & 4.52 & $(5.63)$ & 4.60 & $(5.69)$ \\
\hline Num. Days 50-60 & 5.54 & $(6.61)$ & 5.7 & $(6.67)$ & 4.9 & $(5.68)$ & 5.06 & $(5.76)$ \\
\hline Num. Days $60-70$ & 6.15 & $(6.94)$ & 6.18 & $(6.97)$ & 5.86 & $(6.54)$ & 5.91 & $(6.59)$ \\
\hline Num. Days 70-80 & 5.83 & (8.18) & 5.67 & $(8.10)$ & 6.07 & $(8.26)$ & 5.82 & $(8.16)$ \\
\hline Num. Days > 80 & 1.83 & $(5.51)$ & 1.91 & $(5.65)$ & 1.69 & (5.11) & 1.76 & $(5.28)$ \\
\hline \multirow[t]{5}{*}{$\mathrm{AC}$} & 0.13 & $(0.07)$ & 0.36 & $(0.26)$ & 0.14 & $(0.07)$ & 0.39 & $(0.28)$ \\
\hline & \multicolumn{8}{|c|}{ Panel B: Desegregation Analysis - Southern US States } \\
\hline & & Non- & White & & & & & \\
\hline & \multicolumn{2}{|c|}{$1959-1965$} & \multicolumn{2}{|c|}{ All Years } & \multicolumn{2}{|c|}{ 1959-1965 } & \multicolumn{2}{|c|}{ All Years } \\
\hline & Mean & S.D. & Mean & S.D. & Mean & S.D. & Mean & S.D. \\
\hline PNMR & 163.92 & $(74.71)$ & 96.15 & $(66.44)$ & 47.16 & $(17.22)$ & 34.91 & $(14.82)$ \\
\hline PI/Gastro PNMR & 79.62 & (44.35) & 34.2 & $(40.87)$ & 13.98 & $(9.22)$ & 6.57 & $(7.65)$ \\
\hline Temperature $\left({ }^{\circ} \mathrm{F}\right)$ & 62.57 & (13.84) & 62.54 & $(13.76)$ & 62.54 & (14.02) & 62.51 & (13.96) \\
\hline Num. Days <50 & 7.17 & $(9.96)$ & 6.98 & $(9.77)$ & 7.16 & (10.13) & 6.99 & $(9.96)$ \\
\hline Num. Days 50-60 & 5.10 & $(5.69)$ & 5.21 & $(5.63)$ & 4.94 & $(5.62)$ & 5.07 & $(5.62)$ \\
\hline Num. Days 60-70 & 5.59 & $(5.92)$ & 6.09 & $(6.42)$ & 5.68 & $(6.03)$ & 6.11 & $(6.51)$ \\
\hline Num. Days $70-80$ & 9.52 & (10.17) & 8.9 & $(9.97)$ & 9.64 & $(10.24)$ & 9.01 & (10.09) \\
\hline Num. Days >80 & 3.05 & $(6.71)$ & 3.26 & (7.13) & 3.03 & $(6.84)$ & 3.26 & $(7.27)$ \\
\hline $\mathrm{AC}$ & 0.05 & $(0.03)$ & 0.32 & $(0.25)$ & 0.26 & $(0.1)$ & 0.61 & $(0.25)$ \\
\hline
\end{tabular}

Notes: All summary statistics represent monthly averages. AC is the air conditioning penetration rate measured at the state level. In Panel A, summary statistics are weighted by the county's 1960 population. AMR represents the ageadjusted mortality rate. There are $114 \mathrm{CHC}$ counties (counties that adopted CHCs in the 1965-1974 period) and 2,972 non-CHC counties. In Panel B, summary statistics are weighted by the state's 1960 race-specific population; temperature variables are measured equivalently for non-whites and whites; differences in means for temperature variables reflect differences in weighting. PNMR represents the post-neonatal mortality rate per 100,000 live births. The measure of air conditioning is race-specific in Panel B. 
Table 2: Effects of CHC Access and Temperature on Mortality

\begin{tabular}{lccccc}
\hline & $(1)$ & $(2)$ & $(3)$ & $(4)$ & $(5)$ \\
\cline { 2 - 6 } $\mathrm{CHC}^{t \geq 0}$ & $-1.098^{* * *}$ & & $-1.108^{* * *}$ & & \\
& $(0.306)$ & & $(0.306)$ & & \\
$\mathrm{CHC}^{t \leq-2}$ & & & & -0.123 & -0.127 \\
& & & & $(0.170)$ & $(0.170)$ \\
$\mathrm{CHC}^{0 \leq t \leq 4}$ & & & & $-0.805^{* * *}$ & $-0.820^{* * *}$ \\
& & & & $(0.159)$ & $(0.159)$ \\
$\mathrm{CHC}^{5 \leq t \leq 9}$ & & & & $-1.500^{* * *}$ & $-1.512^{* * *}$ \\
& & & & $(0.264)$ & $(0.263)$ \\
$\mathrm{CHC}^{t \geq 10}$ & & & & $-1.612^{* * *}$ & $-1.627^{* * *}$ \\
& & & & $(0.387)$ & $(0.386)$ \\
$\mathrm{Temp}^{<40}$ & & $0.110^{* * *}$ & $0.110^{* * *}$ & & $0.110^{* * *}$ \\
& & $(0.0154)$ & $(0.0154)$ & & $(0.0153)$ \\
$\mathrm{Temp}^{\geq 80}$ & & $0.176^{* * *}$ & $0.176^{* * *}$ & & $0.176^{* * *}$ \\
& & $(0.0182)$ & $(0.0182)$ & & $(0.0182)$ \\
$N$ & $1,094,760$ & $1,094,760$ & $1,094,760$ & $1,094,760$ & $1,094,760$ \\
\hline
\end{tabular}

Notes: Estimates from each column are from a single regression. The covariates and fixed effects described in Equation (1) are included in all specifications. Standard errors in parentheses are two-way clustered at the county and year-month levels. ${ }^{* *},{ }^{* *},{ }^{*}$ indicate significance at the $0.1 \%, 1 \%$, and $5 \%$ levels, respectively. 
Table 3: Effects of CHC Access on the Temperature-Mortality Relationship

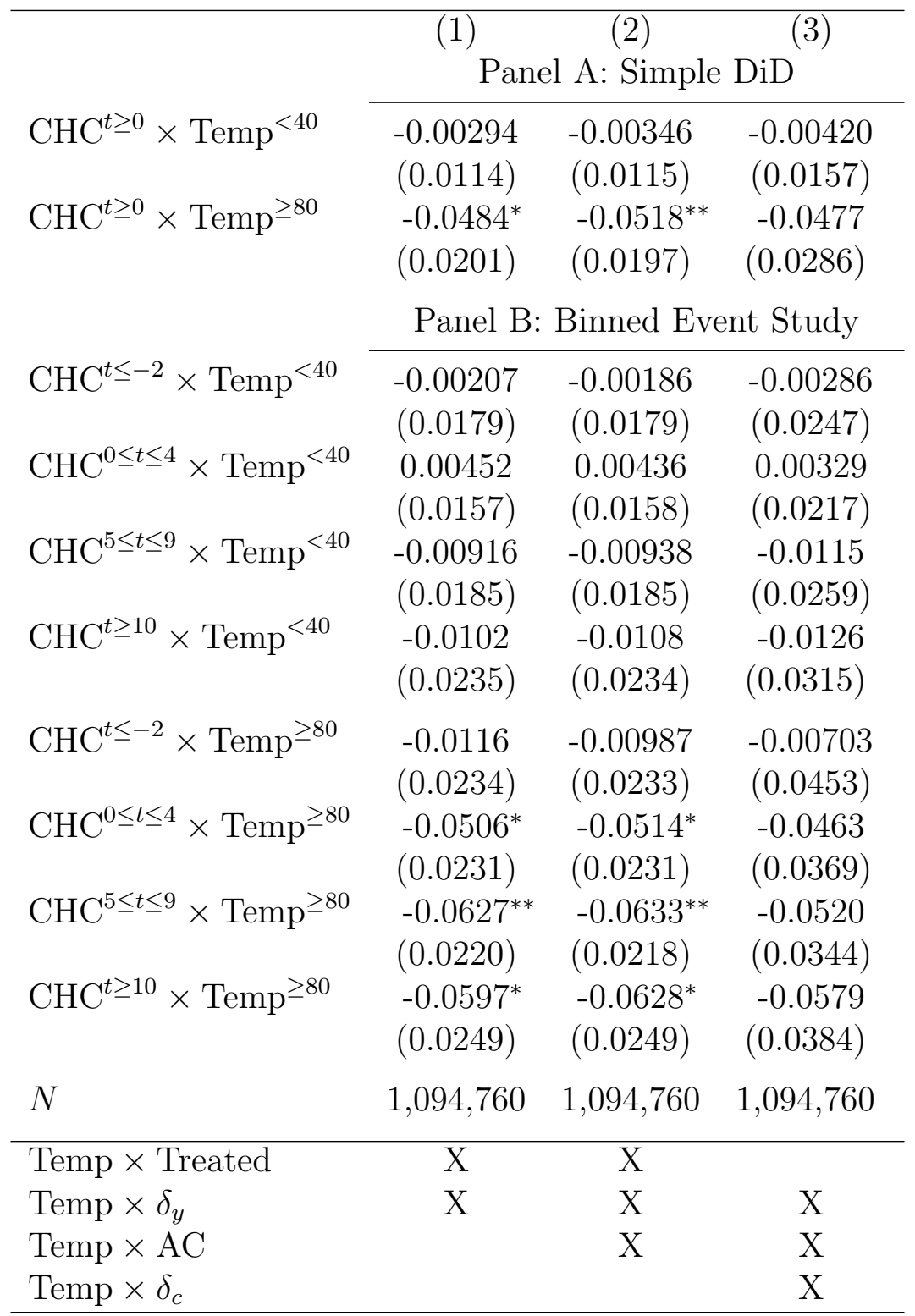

Notes: Within each panel, each column reports coefficient estimates from a single regression. The main effects for temperature and CHC access are included in all specifications. The interacted temperature controls represent controls for all temperature variables included in the model; for example, in Panel C models including "Temp $\times$ Treated" include both Temp ${ }^{<40} \times$ Treated and Temp $>80 \times$ Treated. Standard errors are two-way clustered at the county and year-by-month level. For reference, the baseline estimates for CHC counties in the pre-CHC period (1959-1964) for the effect of a $<40$ and $>80$ day are 0.241 (s.e. $=0.081$ ) and $0.339($ s.e. $=0.070)$, respectively. ${ }^{* * *},{ }^{* *},{ }^{*}$ indicate significance at the $0.1 \%, 1 \%$, and $5 \%$ levels, respectively. 
Table 4: Effects of Desegregation and Temperature on Post-Neonatal Mortality in Southern States

\begin{tabular}{|c|c|c|c|c|c|}
\hline & (1) & $(2)$ & (3) & (4) & (5) \\
\hline $\mathrm{NW} \times \operatorname{Deseg}^{t \geq 0}$ & $\begin{array}{l}-66.03^{* *} \\
(7.622)\end{array}$ & & $\begin{array}{l}-66.03^{\text {*** }} \\
(7.623)\end{array}$ & & \\
\hline $\mathrm{NW} \times \operatorname{Deseg}^{t \leq-2}$ & & & & $\begin{array}{c}8.443 \\
(7.565)\end{array}$ & $\begin{array}{c}8.445 \\
(7.566)\end{array}$ \\
\hline $\mathrm{NW} \times \operatorname{Deseg}^{0 \leq t \leq 4}$ & & & & $\begin{array}{l}-13.24 \\
(8.143)\end{array}$ & $\begin{array}{l}-13.23 \\
(8.144)\end{array}$ \\
\hline $\mathrm{NW} \times \operatorname{Deseg}^{5 \leq t \leq 9}$ & & & & $\begin{array}{l}-53.43^{* * *} \\
(9.806)\end{array}$ & $\begin{array}{l}-53.42^{* * *} \\
(9.808)\end{array}$ \\
\hline $\mathrm{NW} \times \operatorname{Deseg}^{t \geq 10}$ & & & & $\begin{array}{l}-73.12^{\text {*** }} \\
(11.02)\end{array}$ & $\begin{array}{l}-73.12^{* * *} \\
(11.02)\end{array}$ \\
\hline Temp $<50$ & & $\begin{array}{c}0.850^{* *} \\
(0.230)\end{array}$ & $\begin{array}{c}0.850^{* *} \\
(0.230)\end{array}$ & & $\begin{array}{c}0.850^{* *} \\
(0.230)\end{array}$ \\
\hline $\mathrm{Temp}^{>80}$ & & $\begin{array}{c}0.508^{* *} \\
(0.135)\end{array}$ & $\begin{array}{c}0.508^{* *} \\
(0.135)\end{array}$ & & $\begin{array}{c}0.508^{* *} \\
(0.135)\end{array}$ \\
\hline$N$ & 7,200 & 7,200 & 7,200 & 7,200 & 7,200 \\
\hline
\end{tabular}


Table 5: Effects of Desegregation on the Temperature-Mortality Relationship in Southern States

\begin{tabular}{|c|c|c|c|}
\hline $\mathrm{NW} \times \operatorname{Deseg}^{t \geq 0} \times$ Temp $^{<50}$ & \multicolumn{3}{|c|}{ Panel A: Simple DiD } \\
\hline \multirow[t]{2}{*}{$\mathrm{NW} \times \operatorname{Deseg}^{t \geq 0} \times$ Temp $^{>80}$} & $\begin{array}{c}-2.308^{* *} \\
(0.569) \\
0.207 \\
(0.325)\end{array}$ & $\begin{array}{c}-2.648^{* *} \\
(0.710) \\
0.172 \\
(0.329)\end{array}$ & $\begin{array}{c}-2.714^{* *} \\
(0.827) \\
0.0717 \\
(0.355)\end{array}$ \\
\hline & \multicolumn{3}{|c|}{ Panel B: Binned Event Study } \\
\hline $\mathrm{NW} \times \operatorname{Deseg}^{t \leq-2} \times \operatorname{Temp}^{<50}$ & $\begin{array}{l}-1.203 \\
(0.736)\end{array}$ & $\begin{array}{l}-1.560 \\
(0.737)\end{array}$ & $\begin{array}{l}-1.720^{*} \\
(0.735)\end{array}$ \\
\hline $\mathrm{NW} \times \operatorname{Deseg}^{0 \leq t \leq 4} \times \mathrm{Temp}^{<50}$ & $\begin{array}{l}-1.579 \\
(0.716)\end{array}$ & $\begin{array}{l}-1.264 \\
(0.748)\end{array}$ & $\begin{array}{l}-1.183 \\
(0.765)\end{array}$ \\
\hline $\mathrm{NW} \times \operatorname{Deseg}^{5 \leq t \leq 9} \times \mathrm{Temp}^{<50}$ & $\begin{array}{l}-2.936^{* *} \\
(0.765)\end{array}$ & $\begin{array}{l}-2.565^{*} \\
(0.804)\end{array}$ & $\begin{array}{l}-2.466^{*} \\
(0.815)\end{array}$ \\
\hline NW $\times$ Deseg $^{t \geq 10} \times$ Temp $^{<50}$ & $\begin{array}{l}-4.256^{* *} \\
(0.957)\end{array}$ & $\begin{array}{l}-4.305^{* * *} \\
(0.896)\end{array}$ & $\begin{array}{l}-4.384^{* * *} \\
(0.880)\end{array}$ \\
\hline $\mathrm{NW} \times \operatorname{Deseg}^{t \leq-2} \times \mathrm{Temp}^{>80}$ & $\begin{array}{c}0.358 \\
(0.384)\end{array}$ & $\begin{array}{c}0.201 \\
(0.478)\end{array}$ & $\begin{array}{c}0.209 \\
(0.496)\end{array}$ \\
\hline $\mathrm{NW} \times \operatorname{Deseg}^{0 \leq t \leq 4} \times$ Temp $^{>80}$ & $\begin{array}{r}-0.0891 \\
(0.562)\end{array}$ & $\begin{array}{l}0.0547 \\
(0.566)\end{array}$ & $\begin{array}{c}0.0461 \\
(0.558)\end{array}$ \\
\hline $\mathrm{NW} \times \operatorname{Deseg}^{5 \leq t \leq 9} \times$ Temp $^{>80}$ & $\begin{array}{c}0.686 \\
(0.522)\end{array}$ & $\begin{array}{c}0.839 \\
(0.524)\end{array}$ & $\begin{array}{c}0.817 \\
(0.504)\end{array}$ \\
\hline $\mathrm{NW} \times \operatorname{Deseg}^{t \geq 10} \times$ Temp $^{>80}$ & $\begin{array}{c}0.746 \\
(0.550)\end{array}$ & $\begin{array}{c}0.616 \\
(0.628)\end{array}$ & $\begin{array}{c}0.573 \\
(0.633)\end{array}$ \\
\hline$N$ & 7,200 & 7,200 & 7,200 \\
\hline Temp $\times$ NW & $\mathrm{X}$ & $\mathrm{X}$ & $\mathrm{X}$ \\
\hline Temp $\times \delta_{y}$ & $\mathrm{X}$ & $\mathrm{X}$ & $\mathrm{X}$ \\
\hline Temp $\times$ AC & & $\mathrm{X}$ & $\mathrm{X}$ \\
\hline Temp $\times \delta_{s} \times \mathrm{NW}$ & & & $\mathrm{X}$ \\
\hline
\end{tabular}

Notes: The main effects for temperature are included in all specifications, though the coefficients are not presented because their interpretation is obscured by the inclusion of year-specific and geography-specific temperature effects. The interacted temperature controls represent controls for all temperature variables included in the model; for example, models including "Temp $\times$ Non-White" include both Temp ${ }^{<50} \times \mathrm{NW}$ and Temp ${ }^{>80} \times \mathrm{NW}$. The first year of desegregation $(t=0)$ is set to 1966. Standard errors are two-way clustered at the state and year-by-month level. For reference, the baseline estimates for non-whites in the pre-desegregation period (1959-1965) for the effect of a $<50$ and $>80$ day are $2.57($ s.e. $=0.71)$ and 0.74 (s.e. $=0.41$ ), respectively. ${ }^{* * *},{ }^{* *},{ }^{*}$ indicate significance at the $0.1 \%, 1 \%$, and $5 \%$ levels, respectively. 


\section{Appendix}

Figure A1: Trends in Non-White and White Post-Neonatal Mortality (per 100,000 births) in Southern States

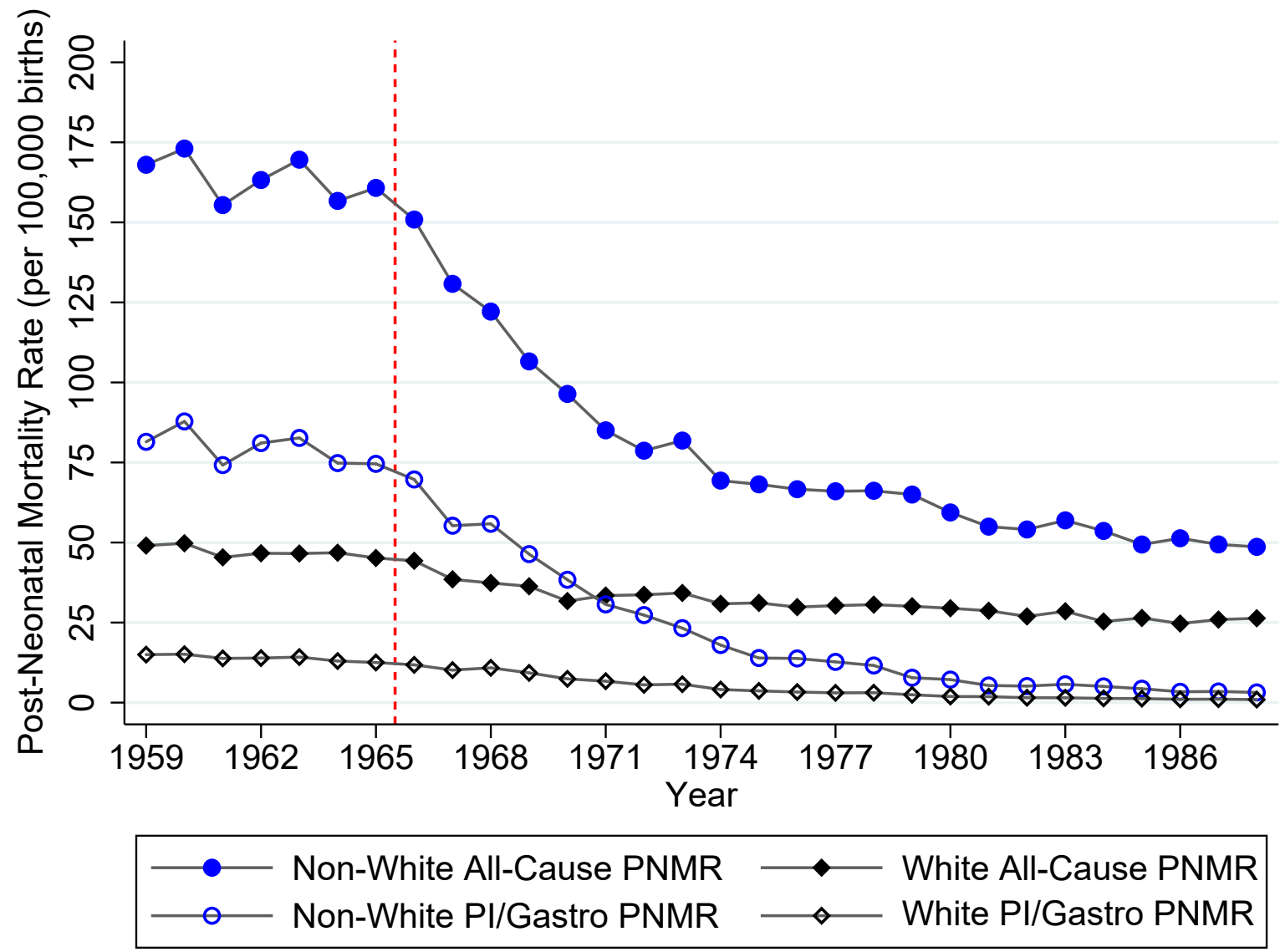

Notes: PNMR is the post-neonatal mortality rate which is the number of deaths of those aged 1 month to 1 year per 100,000 live births in the period. PI/Gastro indicates deaths related to pneumonia/influenza and/or gastroenteritis. 1966 is treated as the first year of desegregation throughout. 
Table A1: Association between CHCs and Temperature Shocks

\begin{tabular}{|c|c|c|c|c|c|}
\hline & Temp $^{>80}$ & Temp $^{<40}$ & $\mathrm{CHC}$ & $\mathrm{CHC}$ & $\mathrm{CHC}$ \\
\hline $\mathrm{CHC}$ & $\begin{array}{c}0.0192 \\
(0.0279)\end{array}$ & $\begin{array}{c}0.0229 \\
(0.0392)\end{array}$ & & & \\
\hline Temp $<40$ & & & $\begin{array}{c}0.0000466 \\
(0.0000793)\end{array}$ & & $\begin{array}{c}0.0000328 \\
(0.0000978)\end{array}$ \\
\hline Temp $^{>80}$ & & & & $\begin{array}{c}0.0000626 \\
(0.0000897)\end{array}$ & $\begin{array}{r}0.0000472 \\
(0.000114)\end{array}$ \\
\hline$N$ & $1,094,760$ & $1,094,760$ & $1,094,760$ & $1,094,760$ & $1,094,760$ \\
\hline
\end{tabular}


Table A2: CHC Interaction Model - All Temperature Bins

\begin{tabular}{|c|c|c|}
\hline \multirow[b]{2}{*}{$\mathrm{CHC}^{t \geq 0} \times \mathrm{Temp}^{<40}$} & \multicolumn{2}{|c|}{$\begin{array}{l}(1) \\
\text { Panel A: Simple DiD }\end{array}$} \\
\hline & $\begin{array}{l}0.00573 \\
(0.0175)\end{array}$ & $\begin{array}{l}-0.0177 \\
(0.0152)\end{array}$ \\
\hline $\mathrm{CHC}^{t \geq 0} \times \mathrm{Temp}^{\geq 80}$ & $\begin{array}{l}-0.0657^{* *} \\
(0.0230)\end{array}$ & $\begin{array}{c}-0.0536^{*} \\
(0.0221)\end{array}$ \\
\hline & \multicolumn{2}{|c|}{ Panel B: Binned Event Study } \\
\hline $\mathrm{CHC}^{t \leq-2} \times \mathrm{Temp}^{<40}$ & $\begin{array}{l}-0.0192 \\
(0.0367)\end{array}$ & $\begin{array}{c}0.00493 \\
(0.0338)\end{array}$ \\
\hline $\mathrm{CHC}^{0 \leq t \leq 4} \times \mathrm{Temp}^{<40}$ & $\begin{array}{c}0.00431 \\
(0.0330)\end{array}$ & $\begin{array}{c}0.00388 \\
(0.0295)\end{array}$ \\
\hline $\mathrm{CHC}^{5 \leq t \leq 9} \times \mathrm{Temp}^{<40}$ & $\begin{array}{l}-0.0172 \\
(0.0375)\end{array}$ & $\begin{array}{l}-0.0131 \\
(0.0341)\end{array}$ \\
\hline $\mathrm{CHC}^{t \geq 10} \times \mathrm{Temp}^{<40}$ & $\begin{array}{l}-0.0200 \\
(0.0418)\end{array}$ & $\begin{array}{r}-0.0281 \\
(0.0394)\end{array}$ \\
\hline $\mathrm{CHC}^{t \leq-2} \times \mathrm{Temp}^{\geq 80}$ & $\begin{array}{r}-0.00403 \\
(0.0336)\end{array}$ & $\begin{array}{l}0.00443 \\
(0.0309)\end{array}$ \\
\hline $\mathrm{CHC}^{0 \leq t \leq 4} \times \mathrm{Temp}^{\geq 80}$ & $\begin{array}{l}-0.0631^{*} \\
(0.0315)\end{array}$ & $\begin{array}{l}-0.0389 \\
(0.0272)\end{array}$ \\
\hline $\mathrm{CHC}^{5 \leq t \leq 9} \times \mathrm{Temp}^{\geq 80}$ & $\begin{array}{l}-0.0689 \\
(0.0356)\end{array}$ & $\begin{array}{l}-0.0487 \\
(0.0299)\end{array}$ \\
\hline $\mathrm{CHC}^{t \geq 10} \times \mathrm{Temp}^{\geq 80}$ & $\begin{array}{l}-0.0724^{*} \\
(0.0357)\end{array}$ & $\begin{array}{r}-0.0556 \\
(0.0303)\end{array}$ \\
\hline$N$ & $1,094,760$ & $1,094,760$ \\
\hline 40-50, 50-60, 70-80 Temp. Vars. \& Ints. & $\mathrm{X}$ & $\mathrm{X}$ \\
\hline Temp $\times$ Treated Controls & $\mathrm{X}$ & $\mathrm{X}$ \\
\hline Temp $\times \delta_{y}$ Controls & $\mathrm{X}$ & $\begin{array}{l}\mathrm{X} \\
\mathrm{Y}\end{array}$ \\
\hline Temp $\times$ AC Controls & & $\mathrm{X}$ \\
\hline
\end{tabular}

Notes: In addition to the $<40^{\circ} \mathrm{F}$ and $>80^{\circ} \mathrm{F}$ temperature bins included in the main specifications, temperature variables for days with mean temperatures $40-50^{\circ} \mathrm{F}, 50-60^{\circ} \mathrm{F}$, and $70-80^{\circ} \mathrm{F}$ are included as well. All relevant interactions are also included for each temperature bin (i.e., the CHC interactions in all specifications and the additional interactions depending on the column). The $60-70^{\circ} \mathrm{F}$ range is the omitted group. No specification with Temp $\times \delta_{c}$ controls is estimated; while it was computationally possible to estimate such a model with two temperature bins, doing so with five temperature bins is infeasible as this would require estimating over 15,000 parameters. Standard errors are two-way clustered at the county and year-by-month level. ${ }^{* * *},{ }^{* *},{ }^{*}$ indicate significance at the $0.1 \%, 1 \%$, and $5 \%$ levels, respectively. 
Table A3: CHC Interaction Model - Trimmed Samples

\begin{tabular}{|c|c|c|c|c|c|c|}
\hline & \multicolumn{6}{|c|}{ Panel A: Simple DiD } \\
\hline $\mathrm{CHC}^{t \geq 0} \times \mathrm{Temp}^{<40}$ & $\begin{array}{c}-0.000620 \\
(0.0135)\end{array}$ & $\begin{array}{c}0.0174 \\
(0.0167)\end{array}$ & $\begin{array}{c}0.0220 \\
(0.0247)\end{array}$ & $\begin{array}{c}-0.00315 \\
(0.0116)\end{array}$ & $\begin{array}{r}-0.00372 \\
(0.0115)\end{array}$ & $\begin{array}{c}-0.000765 \\
(0.0124)\end{array}$ \\
\hline \multirow[t]{2}{*}{$\mathrm{CHC}^{t \geq 0} \times \mathrm{Temp}^{\geq 80}$} & $\begin{array}{l}-0.0343 \\
(0.0187)\end{array}$ & $\begin{array}{l}-0.0330 \\
(0.0225)\end{array}$ & $\begin{array}{l}-0.0239 \\
(0.0310)\end{array}$ & $\begin{array}{l}-0.0598^{* *} \\
(0.0199)\end{array}$ & $\begin{array}{l}-0.0584^{* *} \\
(0.0199)\end{array}$ & $\begin{array}{c}-0.0568^{* *} \\
(0.0206)\end{array}$ \\
\hline & \multicolumn{6}{|c|}{ Panel B: Binned Event Study } \\
\hline $\mathrm{CHC}^{t \leq-2} \times \mathrm{Temp}^{<40}$ & $\begin{array}{l}-0.0171 \\
(0.0239)\end{array}$ & $\begin{array}{l}-0.0377^{*} \\
(0.0169)\end{array}$ & $\begin{array}{l}-0.0192 \\
(0.0239)\end{array}$ & $\begin{array}{c}-0.000947 \\
(0.0169)\end{array}$ & $\begin{array}{r}-0.00155 \\
(0.0169)\end{array}$ & $\begin{array}{l}0.00251 \\
(0.0185)\end{array}$ \\
\hline $\mathrm{CHC}^{0 \leq t \leq 4} \times \mathrm{Temp}^{<40}$ & $\begin{array}{r}-0.00876 \\
(0.0204)\end{array}$ & $\begin{array}{l}-0.0282 \\
(0.0163)\end{array}$ & $\begin{array}{l}-0.0103 \\
(0.0293)\end{array}$ & $\begin{array}{l}0.00221 \\
(0.0151)\end{array}$ & $\begin{array}{l}0.00197 \\
(0.0151)\end{array}$ & $\begin{array}{l}0.00847 \\
(0.0159)\end{array}$ \\
\hline $\mathrm{CHC}^{5 \leq t \leq 9} \times \mathrm{Temp}^{<40}$ & $\begin{array}{l}-0.0208 \\
(0.0243)\end{array}$ & $\begin{array}{r}-0.00772 \\
(0.0203)\end{array}$ & $\begin{array}{c}0.0127 \\
(0.0332)\end{array}$ & $\begin{array}{l}-0.0118 \\
(0.0173)\end{array}$ & $\begin{array}{l}-0.0128 \\
(0.0173)\end{array}$ & $\begin{array}{l}-0.00659 \\
(0.0193)\end{array}$ \\
\hline $\mathrm{CHC}^{t \geq 10} \times \mathrm{Temp}^{<40}$ & $\begin{array}{l}-0.0238 \\
(0.0302)\end{array}$ & $\begin{array}{l}-0.0119 \\
(0.0221)\end{array}$ & $\begin{array}{l}0.00703 \\
(0.0284)\end{array}$ & $\begin{array}{l}-0.0106 \\
(0.0224)\end{array}$ & $\begin{array}{l}-0.0121 \\
(0.0223)\end{array}$ & $\begin{array}{l}-0.00582 \\
(0.0248)\end{array}$ \\
\hline $\mathrm{CHC}^{t \leq-2} \times \mathrm{Temp}^{\geq 80}$ & $\begin{array}{l}-0.0285 \\
(0.0262)\end{array}$ & $\begin{array}{l}-0.0257 \\
(0.0395)\end{array}$ & $\begin{array}{l}-0.0216 \\
(0.0513)\end{array}$ & $\begin{array}{l}-0.0192 \\
(0.0230)\end{array}$ & $\begin{array}{l}-0.0196 \\
(0.0230)\end{array}$ & $\begin{array}{l}-0.0252 \\
(0.0232)\end{array}$ \\
\hline $\mathrm{CHC}^{0 \leq t \leq 4} \times \mathrm{Temp}^{\geq 80}$ & $\begin{array}{l}-0.0548^{*} \\
(0.0225)\end{array}$ & $\begin{array}{l}-0.0567 \\
(0.0401)\end{array}$ & $\begin{array}{l}-0.0382 \\
(0.0537)\end{array}$ & $\begin{array}{l}-0.0532^{*} \\
(0.0220)\end{array}$ & $\begin{array}{l}-0.0528^{*} \\
(0.0219)\end{array}$ & $\begin{array}{l}-0.0528^{*} \\
(0.0220)\end{array}$ \\
\hline $\mathrm{CHC}^{5 \leq t \leq 9} \times \mathrm{Temp}^{\geq 80}$ & $\begin{array}{l}-0.0630^{* *} \\
(0.0233)\end{array}$ & $\begin{array}{l}-0.0594 \\
(0.0382)\end{array}$ & $\begin{array}{l}-0.0474 \\
(0.0542)\end{array}$ & $\begin{array}{l}-0.0711^{* *} \\
(0.0216)\end{array}$ & $\begin{array}{l}-0.0705^{* *} \\
(0.0215)\end{array}$ & $\begin{array}{l}-0.0752^{* * *} \\
(0.0217)\end{array}$ \\
\hline $\mathrm{CHC}^{t \geq 10} \times \mathrm{Temp}^{\geq 80}$ & $\begin{array}{l}-0.0576^{*} \\
(0.0247)\end{array}$ & $\begin{array}{l}-0.0670 \\
(0.0357)\end{array}$ & $\begin{array}{l}-0.0580 \\
(0.0539)\end{array}$ & $\begin{array}{l}-0.0633^{* *} \\
(0.0232)\end{array}$ & $\begin{array}{l}-0.0623^{* *} \\
(0.0232)\end{array}$ & $\begin{array}{l}-0.0677^{* *} \\
(0.0236)\end{array}$ \\
\hline$N$ & 210,600 & 117,720 & 56,160 & $1,093,680$ & $1,078,920$ & 894,240 \\
\hline Standard P-Score & $\mathrm{X}$ & $\mathrm{X}$ & $\mathrm{X}$ & & & \\
\hline $\begin{array}{l}\text { Climate P-Score } \\
\text { P-Score Range }\end{array}$ & {$[0.05,0.95]$} & {$[0.1 .0 .9]$} & {$[0.2,0.8]$} & $\begin{array}{c}\mathrm{X} \\
{[0.05 .0 .95]}\end{array}$ & $\begin{array}{c}\mathrm{X} \\
{[0.1,0.9]}\end{array}$ & $\begin{array}{c}\mathrm{X} \\
{[0.2,0.8]}\end{array}$ \\
\hline
\end{tabular}

Notes: This table replicates the findings from Column 2 of table Table 3, with samples limited to counties within the given propensity score range. ${ }^{* * *},{ }^{* *},{ }^{*}$ indicate significance at the $0.1 \%, 1 \%$, and $5 \%$ levels, respectively. 
Table A4: Desegregation Interaction Model - Wild Cluster Bootstrapped P-Values

\begin{tabular}{|c|c|c|c|}
\hline \multirow[b]{2}{*}{$\mathrm{NW} \times$ Deseg $^{t \geq 0} \times$ Temp $^{<50}$} & \multicolumn{3}{|c|}{ Panel B: Binned Event Study } \\
\hline & $\begin{array}{l}-2.308^{*} \\
{[0.013]}\end{array}$ & $\begin{array}{l}-2.648^{*} \\
{[0.016]}\end{array}$ & $\begin{array}{r}-2.714^{*} \\
{[0.0194]}\end{array}$ \\
\hline $\mathrm{NW} \times \operatorname{Deseg}^{t \geq 0} \times \operatorname{Temp}^{>80}$ & $\begin{array}{c}0.207 \\
{[0.608]}\end{array}$ & $\begin{array}{c}0.172 \\
{[0.640]}\end{array}$ & $\begin{array}{r}0.0717 \\
{[0.765]}\end{array}$ \\
\hline & \multicolumn{3}{|c|}{ Panel B: Binned Event Study } \\
\hline NW $\times \operatorname{Deseg}^{t \leq-2} \times \operatorname{Temp}^{<50}$ & $\begin{array}{l}-1.203 \\
{[0.248]}\end{array}$ & $\begin{array}{l}-1.560 \\
{[0.228]}\end{array}$ & $\begin{array}{l}-1.720 \\
{[0.193]}\end{array}$ \\
\hline $\mathrm{NW} \times \operatorname{Deseg}^{0 \leq t \leq 4} \times \mathrm{Temp}^{<50}$ & $\begin{array}{l}-1.579 \\
{[0.125]}\end{array}$ & $\begin{array}{l}-1.264 \\
{[0.136]}\end{array}$ & $\begin{array}{l}-1.183 \\
{[0.126]}\end{array}$ \\
\hline NW $\times$ Deseg $^{5 \leq t \leq 9} \times$ Temp $^{<50}$ & $\begin{array}{l}-2.936^{*} \\
{[0.041]}\end{array}$ & $\begin{array}{l}-2.565^{*} \\
{[0.047]}\end{array}$ & $\begin{array}{l}-2.466^{*} \\
{[0.034]}\end{array}$ \\
\hline $\mathrm{NW} \times \operatorname{Deseg}^{t \geq 10} \times \operatorname{Temp}^{<50}$ & $\begin{array}{l}-4.256^{*} \\
{[0.018]}\end{array}$ & $\begin{array}{l}-4.305^{*} \\
{[0.017]}\end{array}$ & {$[0.027]$} \\
\hline NW $\times \operatorname{Deseg}^{t \leq-2} \times$ Temp $^{>80}$ & $\begin{array}{c}0.358 \\
{[0.431]}\end{array}$ & $\begin{array}{c}0.201 \\
{[0.451]}\end{array}$ & $\begin{array}{c}0.209 \\
{[0.351]}\end{array}$ \\
\hline $\mathrm{NW} \times \operatorname{Deseg}^{0 \leq t \leq 4} \times \mathrm{Temp}^{>80}$ & $\begin{array}{c}-0.0891 \\
{[0.941]}\end{array}$ & $\begin{array}{l}0.0547 \\
{[0.981]}\end{array}$ & $\begin{array}{l}0.0461 \\
{[0.950]}\end{array}$ \\
\hline NW $\times$ Deseg $^{5 \leq t \leq 9} \times$ Temp $^{>80}$ & $\begin{array}{c}0.686 \\
{[0.326]}\end{array}$ & $\begin{array}{c}0.839 \\
{[0.278]}\end{array}$ & $\begin{array}{c}0.817 \\
{[0.324]}\end{array}$ \\
\hline $\mathrm{NW} \times \operatorname{Deseg}^{t \geq 10} \times \mathrm{Temp}^{>80}$ & $\begin{array}{l}0.746 \\
{[0.368]}\end{array}$ & $\begin{array}{c}0.616 \\
{[0.374]}\end{array}$ & $\begin{array}{c}0.573 \\
{[0.371]}\end{array}$ \\
\hline$N$ & 7,200 & 7,200 & 7,200 \\
\hline $\begin{array}{l}\text { Temp } \times \mathrm{NW} \\
\text { Temp } \times \delta_{y} \\
\text { Temp } \times \text { AC } \\
\text { Temp } \times \delta_{s} \times \mathrm{NW}\end{array}$ & $\begin{array}{l}\mathrm{X} \\
\mathrm{X}\end{array}$ & $\begin{array}{l}\mathrm{X} \\
\mathrm{X} \\
\mathrm{X}\end{array}$ & $\begin{array}{l}X \\
X \\
X \\
X\end{array}$ \\
\hline
\end{tabular}

Notes: This table replicates Table 5 , but with two-way wild cluster bootstrapped p-values in brackets clustered at the state and year-month levels. ${ }^{* * *},{ }^{* *},{ }^{*}$ indicate significance at the $0.1 \%, 1 \%$, and $5 \%$ levels, respectively. 
Table A5: Effects of Desegregation on the Temperature-Mortality Relationship - Quadruple Differences Model

\begin{tabular}{|c|c|c|c|}
\hline & \multicolumn{3}{|c|}{ Panel A: Simple DiD } \\
\hline NW $\times$ Deseg $^{t \geq 0} \times$ Temp $^{<50} \times$ South & $\begin{array}{l}-1.798^{* *} \\
(0.539)\end{array}$ & $\begin{array}{l}-1.831^{* *} \\
(0.547)\end{array}$ & $\begin{array}{l}-1.853^{* *} \\
(0.575)\end{array}$ \\
\hline NW $\times$ Deseg $^{t \geq 0} \times$ Temp $^{>80} \times$ South & $\begin{array}{c}0.911 \\
(0.561)\end{array}$ & $\begin{array}{c}0.856 \\
(0.601)\end{array}$ & $\begin{array}{r}0.814 \\
(0.679)\end{array}$ \\
\hline & \multicolumn{3}{|c|}{ Panel B: Binned Event Study } \\
\hline NW $\times$ Deseg $^{t \leq-2} \times$ Temp $^{<50} \times$ South & $\begin{array}{c}-1.283 \\
(0.666)\end{array}$ & $\begin{array}{l}-1.285 \\
(0.666)\end{array}$ & $\begin{array}{l}-1.309 \\
(0.669)\end{array}$ \\
\hline NW $\times$ Deseg $^{0 \leq t \leq 4} \times$ Temp $^{<50} \times$ South & $\begin{array}{l}-1.432^{*} \\
(0.629)\end{array}$ & $\begin{array}{l}-1.430^{*} \\
(0.627)\end{array}$ & $\begin{array}{l}-1.455^{*} \\
(0.645)\end{array}$ \\
\hline NW $\times$ Deseg $^{5 \leq t \leq 9} \times$ Temp $^{<50} \times$ South & $\begin{array}{l}-2.456^{* *} \\
(0.703)\end{array}$ & $\begin{array}{l}-2.454^{* *} \\
(0.703)\end{array}$ & $\begin{array}{l}-2.485^{* *} \\
(0.720)\end{array}$ \\
\hline NW $\times$ Deseg $^{t \geq 10} \times$ Temp $^{<50} \times$ South & $\begin{array}{l}-3.704^{\text {*** }} \\
(0.895)\end{array}$ & $\begin{array}{l}-3.703^{\text {*** }} \\
(0.894)\end{array}$ & $\begin{array}{l}-3.742^{* * *} \\
(0.934)\end{array}$ \\
\hline NW $\times$ Deseg $^{t \leq-2} \times$ Temp $^{>80} \times$ South & $\begin{array}{l}-0.127 \\
(0.541)\end{array}$ & $\begin{array}{l}-0.183 \\
(0.559)\end{array}$ & $\begin{array}{c}-0.233 \\
(0.608)\end{array}$ \\
\hline NW $\times \operatorname{Deseg}^{0 \leq t \leq 4} \times$ Temp $^{>80} \times$ South & $\begin{array}{r}-0.0191 \\
(0.619)\end{array}$ & $\begin{array}{l}0.0413 \\
(0.613)\end{array}$ & $\begin{array}{c}0.177 \\
(0.641)\end{array}$ \\
\hline $\mathrm{NW} \times$ Deseg $^{5 \leq t \leq 9} \times$ Temp $^{>80} \times$ South & $\begin{array}{c}1.046 \\
(0.638)\end{array}$ & $\begin{array}{c}1.138 \\
(0.636)\end{array}$ & $\begin{array}{c}1.295 \\
(0.682)\end{array}$ \\
\hline NW $\times$ Deseg $^{t \geq 10} \times$ Temp $^{>80} \times$ South & $\begin{array}{c}1.019 \\
(0.688)\end{array}$ & $\begin{array}{c}1.099 \\
(0.682)\end{array}$ & $\begin{array}{c}1.213 \\
(0.716)\end{array}$ \\
\hline$N$ & 35,280 & 35,280 & 35,280 \\
\hline Deseg $\times$ Temp $\times$ NW & $\mathrm{X}$ & $\mathrm{X}$ & $\mathrm{X}$ \\
\hline Temp $\times$ NW $\times$ South & $\mathrm{X}$ & $\mathrm{X}$ & \\
\hline Temp $\times$ South & $\mathrm{X}$ & $\mathrm{X}$ & \\
\hline Temp × NW & $\mathrm{X}$ & $\mathrm{X}$ & $\mathrm{X}$ \\
\hline Temp $\times \delta_{y}$ & $\mathrm{X}$ & $\mathrm{X}$ & $\mathrm{X}$ \\
\hline Temp $\times \delta_{y} \times$ South & $\mathrm{X}$ & $\mathrm{X}$ & $\mathrm{X}$ \\
\hline Temp $\times \mathrm{AC}$ & & $\mathrm{X}$ & $\mathrm{X}$ \\
\hline Temp $\times \delta_{s} \times \mathrm{NW}$ & & & $\mathrm{X}$ \\
\hline
\end{tabular}

Notes: The main effects for temperature are included in all specifications, though the coefficients are not presented because their interpretation is obscured by the inclusion of year-specific and geography-specific temperature effects. The interacted temperature controls represent controls for all temperature variables included in the model; for example, models including "Temp $\times$ Non-White" include both Temp ${ }^{<50} \times \mathrm{NW}$ and Temp ${ }^{>80} \times \mathrm{NW}$. The first year of desegregation $(t=0)$ is set to 1966. Standard errors are two-way clustered at the state and year-by-month level. For reference, the baseline estimates for non-whites in the pre-desegregation period (19591965 ) for the effect of $\mathrm{a}<50$ and $>80$ day are 2.57 (s.e. $=0.71$ ) and 0.74 (s.e. $=0.41$ ), respectively. ${ }^{* * *},{ }^{* *},{ }^{*}$ indicate significance at the $0.1 \%, 1 \%$, and $5 \%$ levels, respectively. 
Table A6: Desegregation Interaction Model - Infant and All-Age Mortality

\begin{tabular}{|c|c|c|c|}
\hline \multirow{3}{*}{$\mathrm{NW} \times \operatorname{Deseg}^{t \geq 0} \times \operatorname{Temp}^{<50}$} & (1) & $(2)$ & $(3)$ \\
\hline & \multicolumn{3}{|c|}{ Panel A: Infants } \\
\hline & $\begin{array}{l}-2.771^{* *} \\
(0.627)\end{array}$ & $\begin{array}{l}-3.174^{* *} \\
(0.823)\end{array}$ & $\begin{array}{l}-3.219^{* *} \\
(0.955)\end{array}$ \\
\hline \multirow[t]{2}{*}{$\mathrm{NW} \times \operatorname{Deseg}^{t \geq 0} \times$ Temp $^{>80}$} & $\begin{array}{l}-0.319 \\
(0.575)\end{array}$ & $\begin{array}{l}-0.753 \\
(0.576)\end{array}$ & $\begin{array}{r}-1.099 \\
(0.540)\end{array}$ \\
\hline & \multicolumn{3}{|c|}{ Panel B: All Ages } \\
\hline $\mathrm{NW} \times \operatorname{Deseg}^{t \geq 0} \times \operatorname{Temp}^{<50}$ & $\begin{array}{c}-0.233^{* *} \\
(0.0561)\end{array}$ & $\begin{array}{c}-0.293^{* *} \\
(0.0653)\end{array}$ & $\begin{array}{c}-0.308^{* *} \\
(0.0780)\end{array}$ \\
\hline $\mathrm{NW} \times \operatorname{Deseg}^{t \geq 0} \times$ Temp $^{>80}$ & $\begin{array}{c}0.119^{*} \\
(0.0457)\end{array}$ & $\begin{array}{c}0.0577 \\
(0.0453)\end{array}$ & $\begin{array}{c}0.0116 \\
(0.0607)\end{array}$ \\
\hline$N$ & 7,200 & 7,200 & 7,200 \\
\hline Temp $\times$ NW & $\mathrm{X}$ & $\mathrm{X}$ & $\mathrm{X}$ \\
\hline Temp $\times \delta_{y}$ & $\mathrm{X}$ & $\mathrm{X}$ & $\mathrm{X}$ \\
\hline Temp $\times$ AC & & $\mathrm{X}$ & $\mathrm{X}$ \\
\hline Temp $\times \delta_{s} \times \mathrm{NW}$ & & & $\mathrm{X}$ \\
\hline
\end{tabular}

Notes: This table presents desegregation results using the infant mortality rate, and the all-age adjusted mortality rate. Recall that our main specification uses post-neonatal mortality following (Almond et al., 2006). For reference, the baseline infant mortality estimates for non-whites in the pre-desegregation period (1959-1965) for the effect of a $<50$ and $>80$ day are 2.92 (s.e.=0.97) and 1.29 (s.e. $=0.81$ ). The baseline all-age mortality estimates for non-whites in the predesegregation period (1959-1965) for the effect of a $<50$ and $>80$ day are 0.76 $($ s.e. $=0.29)$ and 0.29 (s.e. $=0.10) .{ }^{* * *},{ }^{* *},{ }^{*}$ indicate significance at the $0.1 \%, 1 \%$, and $5 \%$ levels, respectively. 


\section{Online Appendix}

\section{Data Details}

\section{Community Health Centers and Covariates}

Data on the timing and location of $\mathrm{CHC}$ establishments, as well as data on all covariates used in Bailey and Goodman-Bacon (2015), were graciously shared by Martha Bailey and Andrew Goodman-Bacon. These data were painstakingly collected through a variety of archival sources including the National Archives Community Action Program, hand-entered Public Health Service Reports, and other primary sources. For all CHCs established in 1965-1974, these data indicate the county in which services are provided, and the year in which the county received its first CHC services grant (as opposed to planning grants). For the purposes of this paper, it is only important that this data provide accurate information on the year and location in which CHC services were first offered; we refer readers to Bailey and Goodman-Bacon (2015) for more detail on the data collection.

\section{Mortality Rates}

Mortality data are derived from the 1959-1988 National Vital Statistics System (NVSS) mortality files maintained by the National Center for Health Statistics (NCHS). For years through 1988, these files are publicly available with county identifiers. We use the a crosswalk between NCHS county codes and FIPS county codes to deal with changes in county coding over time (ICPSR 36603). The NVSS files contain individual-level information on all deaths in the US. Deaths are matched to weather and CHC data based on the year, month, and county of occurrence.

The primary outcome of interest is the age-adjusted mortality rate per 100,000 population. Annual county-level population data by 5-year age groups for the period 1969-2016 are obtained from the Surveillance, Epidemiology, and End Results Program (SEER). Because these data are only available for the period 1969 and beyond, we also use data from the U.S. Census Bureau on county-level population in 1950 and 1960; population data are linearly interpolated for the missing years between 1950 and 1969 .

The main outcome of interest is the age-adjusted mortality rate (AMR). Age-adjusted mortality rates hold fixed the age distribution of the population of a given county such that changes in the AMR reflect changes in the risk of death rather than changes in the age 
structure. ${ }^{33}$

\section{Weather}

The assignment of local weather conditions to population groups is central to our empirical investigation. Our main data source on weather is derived from the PRISM Climate Group (aggregated by Schlenker and Roberts, 2009). This contains daily data on temperature and precipitation for points on a 2.5-by-2.5 mile grid for the U.S. over the period 1959-1988. We aggregate the data to the county level by taking a weighted average of daily temperature and precipitation for all grid points within a county, where the values from each grid point are weighted by the inverse of the squared distance from the grid point to the county's population centroid. Our main temperature variable of interest is the daily mean temperature (the mean of the minimum and maximum temperature). Daily mean temperatures are grouped into $10^{\circ} \mathrm{F}$-wide bins, ranging from $<40^{\circ} \mathrm{F}$ to $>80^{\circ} \mathrm{F}$. The numbers of days in each temperature bin are summed for each county-month in the sample. For analyses at the state level (i.e., the desegregation analysis), we start with data at the county-day level and take the average daily temperature across all counties in the state (weighted by county population). We then sum the state-day data to the state-month level. The independent variables of interest are therefore counts of days for which a given county (or state) had a mean temperature in each bin in a given month and year. Precipitation is measured as the monthly sum.

\section{AC Data}

We follow Barreca et al. (2016) in constructing our measure of AC penetration at the stateyear level. Data on AC penetration are derived from the from the 1960, 1970, and 1980 Censuses. State-year AC penetration rates are interpolated between census years and extrapolated to the ends of the sample. Note that AC penetration rates are also extrapolated across months within the year to avoid discontinuous jumps at the beginning of each year.

\footnotetext{
${ }^{33}$ The AMR for county $c$ at time $t$ is calculated as a weighted average of age-specific mortality rates (ASMR) for county $c$ at time $t$ and 5-year age group $a . A S M R_{c t a}=100,000 \times \frac{\text { Deaths } s_{c t a}}{P_{o p} p_{c t a}} A M R_{c t}=$ $\sum_{a=1}^{18} s_{c a} \times A S M R_{c t a}$, where $s_{c a}$ is the 1960 share of the population in 5-year age group $a$. Age-adjusting refers to holding the population age share $s_{c a}$ fixed.
} 


\section{Empirical Strategy Details}

\section{Generalized CHC Interaction Model}

Please see the following for a generalized empirical model for identifying the interaction between CHC access and temperature. This model allows for $J$ event-study indicators and $G$ temperature bins.

$$
\begin{aligned}
\mathrm{AMR}_{c y m} & =\sum_{j=1}^{J} \sum_{g=1}^{G} \phi^{j g}\left(\mathrm{CHC}_{c y}^{j} \times \operatorname{Temp}_{c y m}^{g}\right)+\sum_{j=1}^{J} \gamma^{j} \mathrm{CHC}_{c y}^{j}+\sum_{g=1}^{G} \pi^{g} \operatorname{Temp}_{c y m}^{g} \\
& +\sum_{g=1}^{G} \theta^{g}\left(\operatorname{Temp}_{c y m}^{g} \times \operatorname{Treated}_{c}\right)+\sum_{g=1}^{G} \kappa^{g}\left(\operatorname{Temp}_{c y m}^{g} \times \mathrm{AC}_{s y}\right)+\sum_{g=1}^{G}\left(\operatorname{Temp}_{c y m}^{g} \times \delta_{y}\right) \\
& +\mu \text { LowPrec }_{c y m}+\rho \operatorname{HighPrec}_{c y m}+\beta \mathrm{X}_{c y}+\delta_{s y}+\delta_{c m}+\delta_{u y}+\delta_{y m}+\varepsilon_{c y m}
\end{aligned}
$$

In practice, our primary specification includes the four event-study indicators $\left(\mathrm{CHC}_{c y}^{t \leq-2}\right.$, $\left.\mathrm{CHC}_{c y}^{0 \leq t \leq 4}, \mathrm{CHC}_{c y}^{5 \leq t \leq 9}, \mathrm{CHC}_{c y}^{t \geq 10}\right)$ used in Bailey and Goodman-Bacon (2015) and two temperature variables $\left(\mathrm{Temp}_{c y m}^{<40}\right.$ and $\left.\mathrm{Temp}_{c y m}^{>80}\right)$ representing both cold and hot temperatures. In this specification, $J=4$ and $G=2$, and the estimates of the eight $\phi^{j g}$ coefficients are of primary interest. The interpretation of one of the $\phi^{j g}$ coefficients is similar to that of a standard event-study coefficient. For example, the interpretation of the coefficient on the interaction $\mathrm{CHC}_{c y}^{0 \leq t \leq 4} \times \mathrm{Temp}_{c y m}^{>80}$ is as follows: the difference in the effect of one additional day $>80^{\circ} \mathrm{F}$ on the age-adjusted mortality rate between the year prior to CHC establishment and the period 0-4 years after. The coefficients on the pre-treatment interactions (e.g., $\mathrm{CHC}_{c y}^{t \leq-2} \times \mathrm{Temp}_{c y m}^{>80}$ ) are expected to be near zero if no differential pre-treatment trends exist in the temperature-mortality relationship. In addition to the binned event study approach, we also estimate a full annual event study, with indicators for each year relative to treatment from $t-9$ to $t+15(J=24)$.

\section{Generalized Desegregation Interaction Model}

The following describes a generalized empirical model for identifying the interaction between Southern hospital desegregation and temperature. This model allows for $J$ event-study indicators and $G$ temperature bins. 


$$
\begin{aligned}
\mathrm{PNMR}_{r s y m} & =\sum_{j=1}^{J} \sum_{g=1}^{G} \phi^{j g}\left(\mathrm{NW}_{r} \times \operatorname{Deseg}_{y}^{j} \times \operatorname{Temp}_{s m y}^{g}\right)+\sum_{j=1}^{J} \gamma^{j}\left(\mathrm{NW}_{r} \times \operatorname{Deseg}_{y}^{j}\right) \\
& +\sum_{g=1}^{G} \pi^{g} \operatorname{Temp}_{s m y}^{g}+\sum_{g=1}^{G} \theta^{g}\left(\operatorname{Temp}_{s m y}^{g} \times \mathrm{NW}_{r}\right)+\sum_{g=1}^{G} \kappa^{g}\left(\mathrm{Temp}_{s m y}^{g} \times \mathrm{AC}_{r s y}\right) \\
& +\sum_{g=1}^{G}\left(\operatorname{Temp}_{s m y}^{g} \times \delta_{y}\right)+\mu \operatorname{LowPrec}_{s m y}+\rho \text { HighPrec }_{s m y}+\delta_{s y}+\delta_{r s m}+\varepsilon_{r s m y}
\end{aligned}
$$

Our main specification is similar to the model for CHCs, with four event-study bins and two temperature variables (here we use Temp $\mathrm{T}_{s m y}^{<50}$ to represent cold temperatures due to the warmer climate in Southern states). Again, the estimates of the eight $\phi^{j g}$ coefficients are of primary interest. In addition to the binned event study approach, we also estimate a full annual event study, with indicators for each year relative to treatment (defined as occurring in 1966) from $t-7$ (i.e., 1959) to $t+18$ (i.e., 1983 and beyond).

\section{Desegregation Quadruple Differences Model}

The following describes a quadruple differences model for identifying the interaction between Southern hospital desegregation and temperature. Relative to the specification described in Equation (4), the model described below includes all states (as opposed to only Southern states), and additionally differences out any changes in temperature-mortality relationship that coincide with the timing of desegregation, but are common across Southern and nonSouthern states. In practice, the model includes an indicator for Southern states $\left(\mathrm{S}_{s}\right)$ interacted with several components of the model.

$$
\begin{aligned}
& \mathrm{PNMR}_{\text {rsym }}=\phi\left(\mathrm{NW}_{r} \times \operatorname{Deseg}_{y}^{t \geq 0} \times \mathrm{Temp}_{\text {sym }} \times \mathrm{S}_{s}\right)+\phi\left(\mathrm{NW}_{r} \times \operatorname{Deseg}_{y}^{t \geq 0} \times \mathrm{Temp}_{\text {sym }}\right) \\
& +\gamma\left(\mathrm{NW}_{r} \times \operatorname{Deseg}_{y}^{t \geq 0} \times \mathrm{S}_{s}\right)+\gamma\left(\mathrm{NW}_{r} \times \operatorname{Deseg}_{y}^{t \geq 0}\right)+\pi_{1} \operatorname{Temp}_{\text {sym }}+\pi_{1}\left(\mathrm{Temp}_{\text {sym }} \times \mathrm{S}_{s}\right) \\
& +\pi_{2}\left(\operatorname{Temp}_{\text {sym }} \times \mathrm{NW}_{r}\right)+\pi_{2}\left(\mathrm{Temp}_{\text {sym }} \times \mathrm{NW}_{r} \times \mathrm{S}_{s}\right)+\mathrm{Temp}_{\text {sym }} \times \delta_{y}+\mathrm{Temp}_{\text {sym }} \times \delta_{y} \times \mathrm{S}_{s} \\
& +\kappa\left(\operatorname{Temp}_{s m y} \times A C_{r s y}\right)+\mu \operatorname{LowPrec}_{s m y}+\rho \mathrm{HighPrec}_{s m y}+\delta_{r s m}+\delta_{s y}+\varepsilon_{\text {rsym }}
\end{aligned}
$$




\section{Details on Robustness Checks}

\section{All Bin Model (Part 1)}

The empirical specifications presented in the body of the paper included only two temperature bins $\left(<40^{\circ} \mathrm{F}\right.$ and $\left.>80^{\circ} \mathrm{F}\right)$. This is preferred due to the smaller number of parameters that need to be estimated and for simplicity in interpretation. That being said, using only the two extreme temperature bins means that the reference group is all days between $40^{\circ} \mathrm{F}$ and $80^{\circ} \mathrm{F}$. Figure 2 shows that estimates for the effect of $<40^{\circ} \mathrm{F}$ days on mortality are much larger when intermediate temperature bins are included. It is natural to ask whether the interaction effects are larger when all of these bins (and relevant interactions and controls) are included as well. Table A2 displays results for a model with five temperature bins ranging from $<40^{\circ} \mathrm{F}$ to $>80^{\circ} \mathrm{F}$, omitting the $60-70^{\circ} \mathrm{F}$ bin as the reference group. The estimates are less precise in comparison to our main specification. The results are qualitatively similar to our main estimates, though it is notable that the estimates for the $<40^{\circ} \mathrm{F}$ interaction effects, while statistically insignificant, are negative and non-trivial in magnitude. The point estimate on $\mathrm{CHC}^{t \geq 10} \times \mathrm{Temp}^{<40}$ implies mitigation of $11.0 \%$. This is again measured relative to the cold-mortality relationship in $\mathrm{CHC}$ counties in the pre-CHC period (Coef. $=0.230$ ).

\section{Trimmed Samples (Part 1)}

Our main specification uses all US counties. While our framework allows for time-invariant differences across counties, it may nonetheless be a concern that $\mathrm{CHC}$ and non-CHC counties are not balanced on observables. To construct treatment and control groups that are more comparable, we follow Crump et al. (2009) and trim the sample based on the propensity of implementing a CHC. We construct two alternative propensity scores by estimating a logit regression of a treatment indicator on various fixed county characteristics. The first is a "Standard" P-Scores based on economic and demographic characteristics, and the second is a "Climate" P-Scores based only on climatic variables. The "Standard" P-Scores is calculated using the following variables (measured in 1960 unless otherwise noted): population density, population density squared, 1950-1960\% population growth, \% nonwhite, $\%$ aged 0-4, \% aged $21+, \%$ aged $65+, \%$ urban, $\%$ rural, $1959 \%$ with income under $\$ 3,000,1959 \%$ with income over $\$ 10,000$, \% less than four years schooling, \% 12 or more years schooling, \% in labor force, unemployment rate, percent male in labor force, housing units per 1,000 population, $\%$ renting, $\%$ households with plumbing, $\%$ households with TV, $\%$ households with telephone, \% households with automobile, median number of rooms, hospitals per 1,000 population, MDs per 1,000 population, and 1957 local government expenditure per 1,000 population. The "Climate" P-Scores is calculated using the following variables: mean 
temperature, mean days in the following bins: $<20^{\circ} \mathrm{F}, 20-30^{\circ} \mathrm{F}, 30-40^{\circ} \mathrm{F}, 40-50^{\circ} \mathrm{F}, 50-60^{\circ} \mathrm{F}$, $70-80^{\circ} \mathrm{F}, 80-90^{\circ} \mathrm{F},>90^{\circ} \mathrm{F}$, and mean precipitation. With these propensity scores in hand, we then restrict the sample to counties with P-Scores in the following three ranges: $[0.05,0.95]$, $[0.1,0.9]$, and $[0.2,0.8]$. Note that $[0.1,0.9]$ is the range suggested by Crump et al. (2009). The results of this exercise are presented in Table A3. Trimming using the "Standard" P-Scores dramatically limits the sample; for example, the $[0.1,0.9]$ trimmed sample consists of 326 counties instead of 3,041 included in the main specification. Because climate is much less useful for predicting CHC establishment, samples trimmed based on the "Climate" P-Scores do not limit the sample as drastically. Reassuringly, the point estimates for the $>80^{\circ} \mathrm{F}$ interactions are very similar across all of the various samples, although estimates with the smaller samples are considerably less precise.

We should also note that the large control group used in the main specification is beneficial along several dimensions: (1) a large control group makes for more 2X2 differencein-differences comparisons that are unconfounded by prior treatment of the control group representative (Goodman-Bacon, 2018a), (2) a large control group allows for separate identification of the effects of time and time relative to treatment (Borusyak and Jaravel, 2017), and (3) in our specific setting, the large control group also contributes to the identification of the temperature effects. 